\title{
Results of the Sea Ice Model Intercomparison Project: Evaluation of sea ice rheology schemes for use in climate simulations
}

\author{
Martin Kreyscher \\ Alfred-Wegener-Institut für Polar- und Meeresforschung, Bremerhaven, Germany \\ Markus Harder and Peter Lemke \\ Institut für Meereskunde an der Universität Kiel, Kiel, Germany \\ Gregory M. Flato \\ Canadian Centre for Climate Modelling and Analysis, Atmospheric Environment Service, \\ University of Victoria, Victoria, British Columbia
}

\begin{abstract}
A hierarchy of sea ice rheologies is evaluated on the basis of a comprehensive set of observational data. The investigations are part of the Sea Ice Model Intercomparison Project (SIMIP). Four different sea ice rheology schemes are compared: a viscous-plastic rheology, a cavitating-fluid model, a compressible Newtonian fluid, and a simple free drift approach with velocity correction. The same grid, land boundaries, and forcing fields are applied to all models. As verification data, there are (1) ice thickness data from upward looking sonars (ULS), (2) ice concentration data from the passive microwave radiometers SMMR and SSM/I, (3) daily buoy drift data obtained by the International Arctic Buoy Program (IABP), and (4) satellite-derived ice drift fields based on the $85 \mathrm{GHz}$ channel of SSM/I. All models are optimized individually with respect to mean drift speed and daily drift speed statistics. The impact of ice strength on the ice cover is best revealed by the spatial pattern of ice thickness, ice drift on different timescales, daily drift speed statistics, and the drift velocities in Fram Strait. Overall, the viscous-plastic rheology yields the most realistic simulation. In contrast, the results of the very simple free-drift model with velocity correction clearly show large errors in simulated ice drift as well as in ice thicknesses and ice export through Fram Strait compared to observation. The compressible Newtonian fluid cannot prevent excessive ice thickness buildup in the central Arctic and overestimates the internal forces in Fram Strait. Because of the lack of shear strength, the cavitating-fluid model shows marked differences to the statistics of observed ice drift and the observed spatial pattern of ice thickness. Comparison of required computer resources demonstrates that the additional cost for the viscous-plastic sea ice rheology is minor compared with the atmospheric and oceanic model components in global climate simulations.
\end{abstract}

\section{Introduction}

Sea ice affects the climate at high latitudes by insulating the ocean from the atmosphere. The dynamics of the sea ice cover, advection and deformation, controls its presence and properties in space and time by transporting the sea ice over large distances, shifting the ice

Copyright 2000 by the American Geophysical Union.

Paper number 1999JC000016.

0148-0227/00/1999JC000016\$09.00 margin and producing open water areas within the ice pack.

Associated with the large-scale transport of sea ice are fluxes of freshwater, heat and momentum, which influence the state of the ocean, and the overlying atmosphere. The global conveyor belt circulation of the ocean is believed to be forced in the North and South Atlantic through deep water formation. Sea ice production plays a major role in the intensity of this forcing mechanism, whereas the sea ice export to the lower latitudes stabilizes the stratification of the upper ocean in the regions where sea ice melts. Advection of sea 
ice also defines the shape of the ice edge and modifies the ice extent by importing sea ice into regions where pure thermodynamic processes would not allow sea ice occurrence.

The deformation of the sea ice cover controls the ice thickness buildup and the formation of leads (open water areas within the ice pack). Even though leads occupy only a small fraction of the ice-covered area in the polar regions, they dominate the turbulent heat exchange in winter by exposing the relatively warm ocean water to the cold atmosphere. In summer, open water areas with a much lower albedo than sea ice lead to an increased short-wave absorption in the ocean.

The importance of the role of sea ice dynamics in the climate system has been shown by model simulations. For example experiments with stand-alone sea ice models [e.g., Hibler, 1984; Lemke et al., 1990] have shown that thermodynamic-only models are more sensitive to changes in thermal forcing than those that include dynamics. Similarly, general circulation models (GCMs) appear to be less sensitive to global warming induced by $\mathrm{CO}_{2}$ doubling when dynamics of sea ice is incorporated into the climate simulation [Pollard and Thompson, 1994].

Despite the apparent impact of sea ice dynamics on the climate system, many GCMs use pure thermodynamic sea ice models or models with simplified advection schemes [Intergovernmental Panel on Climate Change (IPCC), 1996]. Only a few GCMs use more sophisticated dynamic-thermodynamic sea ice models where the internal forces in the ice cover are described by a sea ice rheology. Examples include the use of the cavitating-fluid formulation [Flato and Hibler, 1992] in models developed at the National Center for Atmospheric Research (NCAR) and Commonwealth Scientific and Industrial Research Organisation (CSIRO) and the use of a viscous-plastic rheology scheme [e.g., Hibler, 1979] in the ECHAM/OPYC coupled model [Oberhuber, 1992].

This raises the following questions: What impact do the different sea ice rheologies have on the large-scale properties of the sea ice cover? What features should an appropriate description of internal sea ice stresses for the use in climate simulations incorporate? To answer these questions is a main task of the Sea Ice Model Intercomparison Project (SIMIP) [Lemke et al., 1997; Kreyscher et al., 1997; Kreyscher, 1998], a subproject of the Numerical Experimentation Group (NEG) of the Arctic Climate System Study (ACSYS) within the World Climate Research Programme (WCRP).

This task includes the following aspects: to run a hierarchy of sea ice models using the same grid and forcing data, to compare the results obtained from the different simulations, and to define error functions based on observational data to evaluate sea ice dynamic schemes.

The model hierarchy includes a simple free drift model with velocity corrections (based on Bryan [1969]), a compressible Newtonian fluid, a cavitating-
Aluid model [Flato and Hibler, 1992], and a viscousplastic model (based on Hibler [1979]). The Newtonian fluid model is the only approach that has not been used in GCMs but has been included as another ad hoc scheme that is based on a solution of a physically realizable momentum equation.

All models use the same thermodynamic formulation and the same forcing for the 17 years 1979-1995. Details of model physics and numerics are described by, for example, Harder and Lemke [1994], Harder [1996], and Steiner et al. [1998]. It should be noted that it is clear from the outset that the viscous-plastic model is the most complete physical approach in the model hierarchy. It is not the goal of this paper to reconfirm this fact but to reveal the defiencies of the models in detail in order to estimate the impact of these for climate simulations.

The simulation results from all models in the hierarchy are then evaluated under two viewpoints. First, the differences between the model results are described, quantified, and, as far as possible, explained by the different model physics. This is done in the manner of a sensitivity study, where one rheology module is replaced by a different one, and the overall effect on the simulation results in terms of sea ice properties is investigated. It is clear that the overall effect of the rheology scheme on the simulation includes both direct effects, such as the modification of the momentum balance by the physical model for the internal forces, as well as indirect effects, such as modifications in thermodynamics, which in turn have a feedback effect on ice strength and rheology.

The second part of the evaluation of the model hierarchy is the comparison of simulated ice properties with observations. Our question is whether the implementation of a physically founded ice rheology provides for better agreement with observations than simple ad hoc approaches for the effect of internal forces. It is clear that differences between simulation results and observations originate for a number of reasons, many of them not being (directly) related to ice rheology: inaccuracies in the forcing fields, errors in the observations, limited resolution in space and time, and simplifications of physics in various parts of the model, both dynamics and thermodynamics. Even with a perfect ice rheology, we would not expect absolute agreement between observations and simulation results.

The objective of our study is to investigate to which extent the right choice of rheology improves the simulation for a given set of forcing and observational data. We present the comparison of model simulations with observed ice thickness data from upward looking sonar, ice extent series from passive microwave radiometers on satellites, ice drift data from drifting buoys, and satellite-derived ice motion fields (Figure 1). An additional focus is on the simulated Fram Strait ice exports because this freshwater flux represents one of the most important sea ice variables in the climate context. 


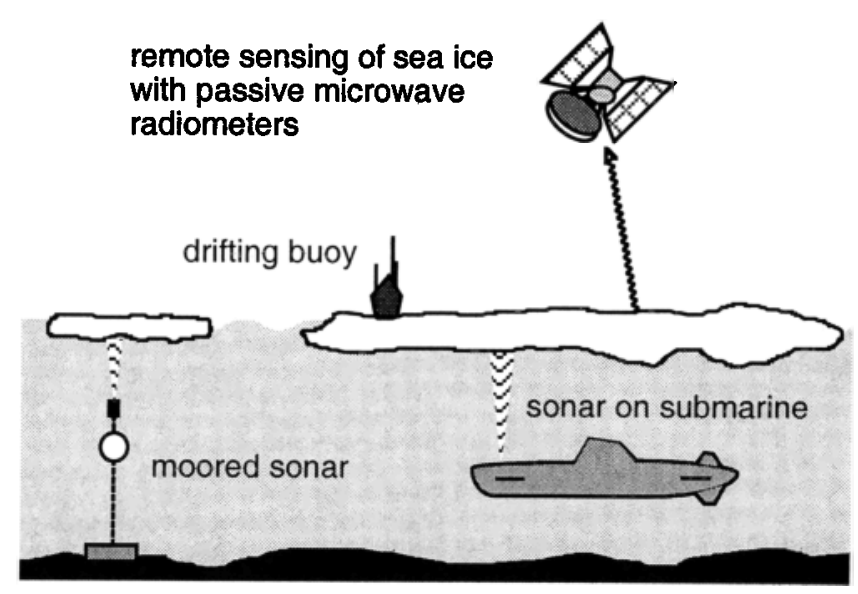

Figure 1. Schematic overview of the data sources used for the verification of sea ice rheologies.

\section{Model Description}

\subsection{Dynamics}

For numerical simulation, sea ice is considered a twodimensional continuum in dynamical contact with the ocean and the atmosphere. The momentum equation for sea ice, with the inertial term neglected, is described by the vector equation

$$
-m f \mathbf{k} \times \mathbf{u}+\tau_{a}+\tau_{w}-m g \nabla H+\mathbf{F}=\mathbf{0},
$$

where $m$ is the ice mass per unit area, $\mathbf{u}$ is the horizontal ice velocity, $f$ is the Coriolis parameter, $\mathbf{k}$ is a unit vector normal to the surface, $\tau_{a}$ and $\tau_{w}$ are the nonlinear air and water stresses, $g$ is the acceleration due to gravity, $H$ is the sea surface dynamic height, and $\mathbf{F}$ is the internal ice force caused by interactions between adjacent ice flows. Neglecting the inertial term for climate simulations is a reasonable approximation since it has been shown that for temporal averages of 1 day or longer, inertial forces are several orders of magnitude smaller than other forces acting on the ice pack [Harder, 1996; Steele et al., 1997]. (Some climate models use a time step much shorter than a day for sea ice dynamics. However, this is due to numerical reasons and is not intended to resolve all high-frequency processes, such as tidal and inertial motion. In particular, the ice-ocean drag parameterization given below is only applicable if these high-frequency oscillations are filtered out [Geiger et al., 1998].)

The air- and water-drag stresses are obtained from quadratic formulations [e.g., McPhee, 1975]:

$$
\begin{aligned}
\tau_{a}= & \rho_{a} c_{a}\left|\mathbf{u}_{a}\right|\left[\mathbf{u}_{a} \cos \Phi+\mathbf{k} \times \mathbf{u}_{a} \sin \Phi\right], \\
\boldsymbol{\tau}_{w}= & \rho_{w} c_{w}\left|\mathbf{u}_{w}-\mathbf{u}\right|\left[\left(\mathbf{u}_{w}-\mathbf{u}\right) \cos \Theta\right. \\
& \left.+\mathbf{k} \times\left(\mathbf{u}_{w}-\mathbf{u}\right) \sin \Theta\right]
\end{aligned}
$$

where $\rho_{a}$ and $\rho_{w}$ are the densities of air and water, $\mathbf{u}_{a}$ and $\mathbf{u}_{w}$ are wind velocities at $10 \mathrm{~m}$ height and geostrophic ocean current velocities, $\Phi\left(=0^{\circ}\right)$ and $\Theta(=$ $\left.25^{\circ}\right)$ are wind and water turning angles, and $c_{a}$ and $c_{w}$ are wind and water drag coefficients, respectively. The ratio $c_{a} / c_{w}$ is used to optimize the mean sea ice drift speed (section 2.4).

The description of the internal ice forces is the focus of the present paper. $\mathbf{F}$ is calculated as the divergence of a stress tensor $\sigma$. The functional dependence of the stress tensor on the ice velocity field (deformation or deformation rate) is expressed by a constitutive law. In the past a number of rheologies were discussed [e.g., Campbell, 1966; Coon et al., 1974; Rothrock, 1975; Hibler, 1979; Flato and Hibler, 1992; Ip, 1993; Hibler and Ip, 1995; Ukita and Moritz, 1995]. The aim of this paper is to compare a representative sample relevant to climate simulations. Therefore a model hierarchy of four different sea ice rheologies is applied, including a viscous-plastic rheology, a cavitating-fluid model, a compressible Newtonian fluid, and a simple free-drift model with velocity correction. This selection is not intended to be complete or general. The motive for selecting these models was that three of them are currently used in climate models, and the fourth, the compressible Newtonian fluid, is included as a linearviscous approach. With the viscous-plastic model the model hierarchy contains a physically complete scheme that is often used in sea ice simulations. The extensive evaluation of the model results identifies sensitive error functions, which can be used to accomplish further investigations, also with other models, in the future.

2.1.1. Viscous-plastic model. The viscousplastic model (VPM) is based on Hibler [1979]. Sea ice is considered a plastic compressible medium obeying the constitutive law

$$
\sigma_{i j}=2 \eta \dot{\epsilon}_{i j}+(\zeta-\eta) \dot{\epsilon}_{k k} \delta_{i j}-\frac{P}{2} \delta_{i j}
$$

where $\zeta$ and $\eta$ are nonlinear bulk and shear viscosities depending on strain rate $\dot{\epsilon}, \delta_{i j}$ is the Kronecker symbol, and the pressure term $P$ is a function of ice thickness characteristics and the strain rate.

There are two modifications of the original formulation by Hibler [1979]. The viscosities are related to the strain rates such that the stress state lies on a truncated elliptical plastic yield curve, which is constrained to lie within the third quadrant of principle stress space (Figure 2). The basic idea of the truncated ellipse is to reduce the shear viscosity in such a way that the maximum shear stress is reduced to prevent any tensile stress [Hibler and Schulson, 1997, appendix]. This modified yield curve takes into account the mathematical instability addressed by Gray and Killworth [1995].

The second alteration pertains to the treatment of the creep closure scheme. In Hibler's original scheme the viscosities take on some maximum value when the strain rates become small enough, which yields a stress state inside the plastic yield curve (viscous regime). In the case of an elliptical yield curve these stress states lie on ellipses concentric about the center of the ellipse. 


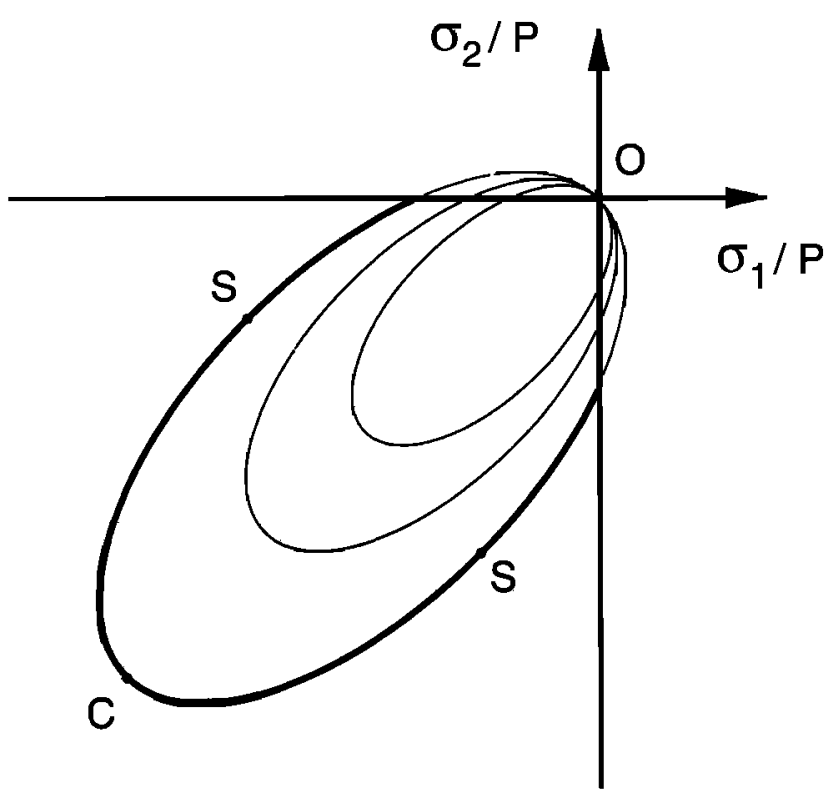

Figure 2. Elliptical yield curve (thin curve) after $\mathrm{Hi}$ bler [1979], truncated elliptical yield curve (thick) $[\mathrm{Hi}$ bler and Schulson, 1997], and replacement closure for viscous regime (concentric thin curves inside the large elliptical yield curve) [Ip, 1993; Harder, 1996; Hibler and Schulson, 1997] in principal stress space. For plastic flow, the stress states lie on the thick curve with the location dictated by the ratio of the strain rate principal components. The stress state for pure shearing deformation is located at $S$ and for isotropic compression at $C$. For very small strain rates, the stress states lie inside the yield curve as illustrated by the thin curves.

This has the disadvantage that in the absence of any deformation there is a pressure that tends to cause divergent ice drift. A closure scheme that avoids this drawback, the so-called replacement closure, is to take the pressure to depend on the deformation rate in such a way that the creep stress states lie on geometrically similiar curves that all go through the origin of the principle stress space (Figure 2) [Ip, 1993; Harder, 1996; Hibler and Schulson, 1997]. We follow the formulation of Harder [1996] where the bulk and shear viscosities $\zeta$ and $\eta$ are described as

$$
\begin{aligned}
\zeta & =\frac{P_{p}}{2\left(\Delta+\Delta_{\min }\right)} \\
\eta & =\frac{P_{p}}{2 e^{2}\left(\Delta+\Delta_{\min }\right)}, \\
P & =\frac{P_{p} \Delta}{2\left(\Delta+\Delta_{\min }\right)},
\end{aligned}
$$

where $P_{p}$ is the ice strength parameterized by ice thickness and ice concentration, and

$$
\begin{aligned}
\Delta(\dot{\varepsilon})= & {\left[\left(\dot{\varepsilon}_{11}^{2}+\dot{\varepsilon}_{22}^{2}\right)\left(1+e^{-2}\right)+4 e^{-2} \dot{\varepsilon}_{12}^{2}\right.} \\
& \left.+2 \dot{\varepsilon}_{11} \dot{\varepsilon}_{22}\left(1-e^{-2}\right)\right]^{\frac{1}{2}},
\end{aligned}
$$

is a kinematic measure for the total amount of deformation [Hibler, 1979]. The constant regime parameter

$$
\Delta_{\min }=5 \times 10^{-9} \mathrm{~s}^{-1}
$$

is small compared with $\Delta(\dot{\varepsilon})$ in the case of typical deformation rates. The eccentricity $e$ of the elliptical yield curve is taken to be 2 in all simulations [Hibler, 1979].

The ice strength is parameterized as

$$
P_{p}=P^{*} h \exp \{-20(1-A)\},
$$

where $P^{*}$ is a strength parameter $\left(\mathrm{N} \mathrm{m}^{-2}\right), h$ is the mean ice thickness (m), and $A$ is ice compactness. $P^{*}$ essentially determines the magnitude of ice strength and is used to optimize the ice drift statistics (section 2.4).

2.1.2. Cavitating-fluid model. The cavitatingfluid model (CFM) [Flato and Hibler, 1992] assumes pack ice to have a plastic behavior in the case of compressive deformation and allows divergence without any internal stresses. In contrast to the viscous-plastic model, this idealized medium has no shear strength.

To put this into the context of the yield curve shown for the viscous-plastic model (Figure 2), consider an ellipse such that the ratio of major to minor axes (eccentricity $e$ ) gets larger and larger. In the limit of an infinite ratio, one obtains the cavitating-fluid model. Stress states for convergence and divergence can only occur at the two endpoints of the yield line (points $\mathrm{C}$ and $\mathrm{O}$, respectively). Other points on the line represent pure shear deformation. This makes the model simple to formulate and implement. The internal ice stress term of equation (1) can now be expressed simply as

$$
\mathbf{F}=-\nabla p,
$$

where $p$ is the internal ice pressure:

$$
\begin{array}{rll}
p=P_{p} & \text { for } & \nabla \mathbf{u}<0 \\
p \in\left[0, P_{p}\right] & \text { for } & \nabla \mathbf{u}=0 \\
p=0 & \text { for } & \nabla \mathbf{u}>0 .
\end{array}
$$

The compressive strength parameterization $P_{p}$ is the same as in the viscous-plastic model (equation (10)).

2.1.3. Compressible Newtonian fluid. A linearviscous approach is the compressible Newtonian fluid (CNF). For this rheology the bulk and shear viscosities of equations (5) plus (6) depend on the ice properties but not on the strain rate. This leads to linear-viscous behavior and tensile stresses. The viscosities are prescribed as

$$
\begin{gathered}
\zeta=\frac{P_{p}}{2 \Delta_{0}}, \\
\eta=0.05 \zeta,
\end{gathered}
$$

with the constant $\Delta_{0}=10^{-7} \mathrm{~s}^{-1}$ as a mean value for $\Delta$ (equation (8)) for typical deformation rates, and with the ice strength $P_{p}$ being defined in equation (10). The pressure term $-\frac{P}{2} \delta_{2 j}$ in equation (4) is set to zero independent of the deformation state.

Similar to a thin "honey film" the CNF resists convergent and divergent deformation with the same amount 
of internal stresses, whereby the stresses depend linearly on the deformation rate. The constant bulk and shear viscosities make the numerics of the CNF very simple in comparison with the VPM and the CFM, which require several iterations for alternating calculations of the velocity and the viscosity fields [Hibler, 1979; Flato and Hibler, 1992; Zhang and Hibler, 1997].

2.1.4. Free-drift model with velocity correction. The simplest model within the model hierarchy is the free-drift model with velocity correction (FDC). This scheme starts with the free-drift solution of equation (1), that is, the internal ice forces $\mathbf{F}$ are set to zero. The main problem of a pure free-drift model is that the neglect of internal ice forces causes exessive ice thickness buildup in regions with mainly convergent deformation (e.g., north of the Canadian archipelago). To supress this effect, a subsequent correction step for the volocities is applied. All velocity components are set to zero where (1) the ice thickness exceeds a critical ice thickness $h_{\max }$ and (2) the ice would be advected from thinner to thicker ice conditions. This approach is derived from the model of Bryan [1969].

\subsection{Thermodynamics}

For the comparison of the different dynamic schemes all models use the same thermodynamic formulation and parameterization similar to Hibler [1979]. Thermodynamics is kept simple for these dynamics studies but still provides for a reasonable seasonal cycle of the ice thickness. The important point here is that all dynamics schemes are forced with identical thermodynamic formulations. An intercomparison of different thermodynamic schemes is beyond the scope of this study but has been done, for example, by Fichefet and Morales Maqueda [1997].

The continuity equations for the three prognostic variables ice thickness $h$, snow thickness $h_{s}$, and ice concentration $A$ can be written as

$$
\begin{aligned}
\frac{\partial h}{\partial t}+\nabla(\mathbf{u} h) & =G_{h} \\
\left.\frac{\partial h_{s}}{\partial t}+\nabla \mathbf{u} h_{s}\right) & =G_{s} \\
\frac{\partial A}{\partial t}+\nabla(\mathbf{u} A) & =G_{A}
\end{aligned}
$$

where $G_{h}, G_{s}$, and $G_{A}$ are the thermodynamic growth rates of the corresponding variables. The thermodynamic growth rates are modeled essentially as by Parkinson and Washington [1979], using a surface energy balance and the Semtner [1976] zero-layer approach for heat conduction through snow and ice. Thermodynamic calculations are performed seperately for open water and seven thickness categories following $\mathrm{Hi}$ bler [1984], assuming a uniform distribution of ice thickness between zero and twice the mean ice thickness.

A fixed-mixed layer ocean model (25 m depth) is implemented, which stores heat during ice-free seasons. Ice is allowed to form only when the mixed layer cools to the freezing point $(271.2 \mathrm{~K})$. To parameterize horizontal ocean heat transport and vertical mixing, a climatological seasonal cycle of heat fluxes into the upper mixed layer is prescribed, which is derived from a coupled sea-ice-ocean model [Hibler and Zhang, 1993].

\subsection{Grid Configuration and Forcing}

All models use the same grid configuration, land boundaries, and forcing fields. The prognostic equations are solved on a rotated spherical grid (with the model pole at $0^{\circ} \mathrm{N} 60^{\circ} \mathrm{O}$ in the Indian Ocean and the model equator along the $30^{\circ} \mathrm{W}$ meridian) with a resolution of $1^{\circ} \times 1^{\circ}$ for the whole Arctic (Figure 3). The time step is 1 day. Following Zhang and Hibler [1997], 30 pseudo time steps per real-time step are used to obtain fully plastic flow. Free outflow to the North Atlantic and through Bering Strait is allowed. The models use an Arakawa B-grid finite difference formulation for the description of scalar variables. Momentum equations are solved on an Arakawa B-grid for the viscousplastic model and the compressible Newtonian fluid. The cavitating-fluid model and the free-drift model with velocity correction both use an Arakawa C-grid for numerical stability [Bryan, 1969; Flato and Hibler, 1992]. The effect of the grid type on the model results, which is generally small for the monthly mean fields, is described by Flato and Hibler [1992, appendix A]. The advection terms are calculated using upstream differencing. As for thermodynamics, the same scheme is applied for all models. We do not expect the results of our dynamics intercomparison study to depend strongly on the choice

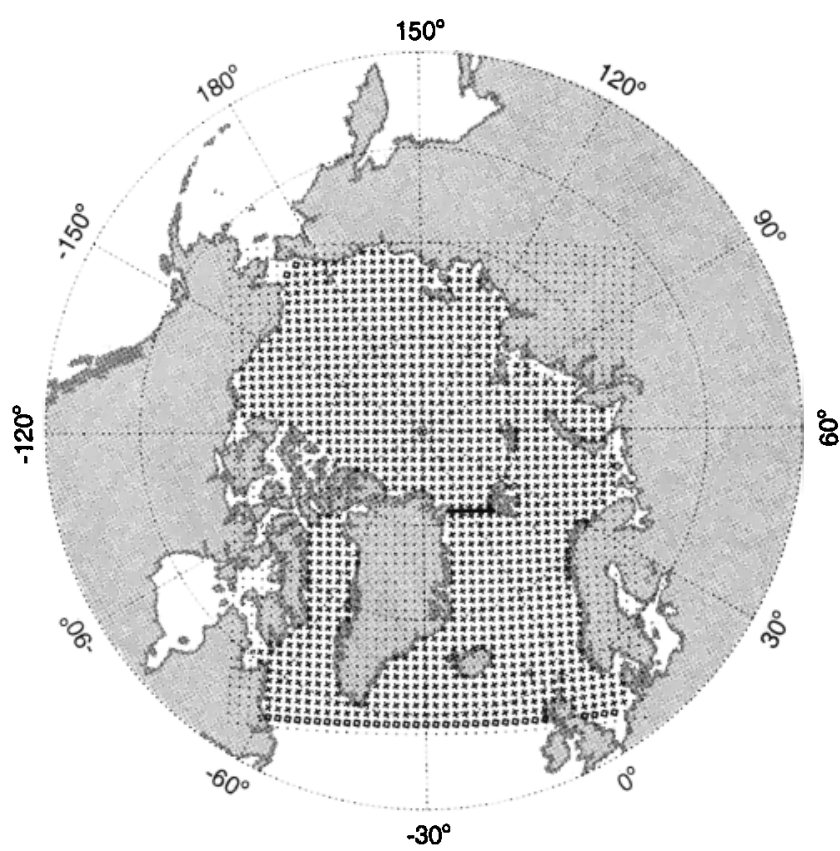

Figure 3. Model grid for scalar variables in the Arctic Ocean. Crosses mark water grid cells where sea ice may be formed. Rhombuses define outflow points. The solid line in Fram Strait indicates the grid points where the ice export is calculated. 
of advection scheme because this does not directly enter the momentum equation, which is the focus here.

Atmospheric forcing data for the 17 year period 19791995 are derived from the National Centers for Environmental Prediction/National Center for Atmospheric Research (NCEP/NCAR) reanalyses [Kalnay et al., 1996]. The NCEP/NCAR $10 \mathrm{~m}$ wind and $2 \mathrm{~m}$ temperature fields are averaged to daily means. This gives a wind forcing with realistic variability on daily and longer timescales. The reanalysis data provide a consistent forcing data set for the whole time period. Because of problems with the NCEP/NCAR humidities, relative humidity at $2 \mathrm{~m}$ height derived from the analyses of the European Centre for Medium-Range Weather Forecasts (ECMWF) are prescribed as climatological, spatially varying monthly means. We use a climatology instead of daily values for the humidity because the ECMWF analyses are not consistent with the NCEP/NCAR reanalyses on a daily base. A seasonally and spatially varying heat flux from the deep ocean into the mixed layer is obtained from a coupled sea-ice-ocean simulation [Hibler and Zhang, 1993] as well as a climatological annual mean geostrophic current and associated seasurface tilt. Spatially constant climatological monthly means of cloudiness and precipitation are taken from Ebert and Curry [1993] and Vowinckel and Orvig [1970], respectively.

All models start with an ice-free ocean. After one spin-up cycle of 7 years of forcing data (1979-1985) the model has reached a quasi-cyclostationary state, which serves as an initial condition for the subsequent study. The model results for the intercomparison are then taken from a second, 17 year cycle (1979-1995). Using the spin-up period makes sure that the ice thickness and concentration fields of each model, whichever rheology is used, are in approximate equilibrium with the forcing data.

\subsection{Model Optimization}

The numerical description of the various sea ice rheologies is based on a number of parameters. Some of these parameters are fixed or restricted to a range obtained from measurements, while others are not directly measurable (e.g., large-scale ice-strength parameter $P^{*}$ ). The models predict unrealistic simulation results if inadequate parameter configurations are applied. Some deficiencies of numerical models can be attributed to a poor choice of parameter values, whereas other discrepancies are caused by oversimplified model physics. To reveal these physical drawbacks, it is necessary to optimize all models individually with respect to the major dynamic parameters.

While the most straightforward optimization would be based on several simulations with several simultaneously varied parameters, that procedure required hundreds of runs for each rheology model, which well exceeds reasonable amounts of computational cost. Here
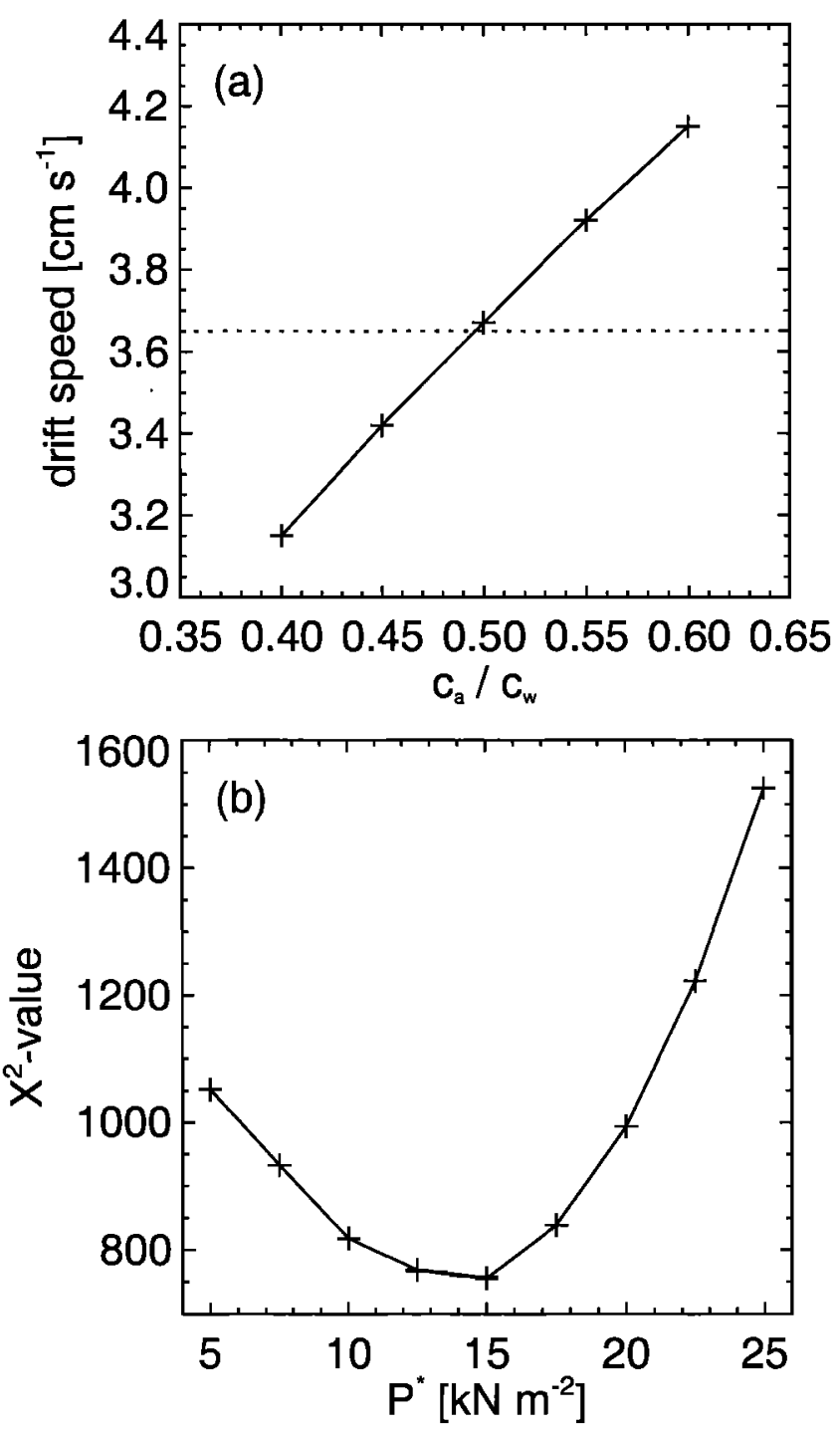

Figure 4. Results of the optimization procedure for the viscous-plastic model: (a) dependence of mean monthly drift speed on the ratio of air and water drag coefficients (dashed line: observed mean drift speed), (b) mean $\chi^{2}$-values of simulated speed distributions for four seasons and four regions (for details see section 5.3.1).

we use a simpler, iterative scheme for the optimization, which could be easily repeated with other, possibly coupled models.

In a first step the ratios of air and water drag coefficients $c_{a} / c_{w}$ (equations (2) and (3)) are optimized for all models. The $c_{a} / c_{w}$ is an important parameter for determining the mean drift speed in the simulations [Harder and Fischer, 1999; Geiger et al., 1998]. For higher ratios the air drag increases, which speeds up the model ice drift. We start our optimization with the ratio $c_{a} / c_{w}$ considered as the "most basic" dynamics parameter because the drag coefficients influence the ice drift in all regions during all seasons. In contrast, the ice strength parameter $P^{*}$ has a strong impact only in areas of thick, compact ice pack, whereas its influence 
Table 1. Parameter Configurations for Optimized Ice Drift Statistics

\begin{tabular}{llll}
\hline Ice Dynamics Scheme & $c_{a} / c_{w}$ & $P^{*}\left(\mathrm{~N} \mathrm{~m}^{-2}\right)$ & $h_{\max }(\mathrm{m})$ \\
\hline VPM & 0.5 & 15000 & - \\
CFM & 0.38 & 27500 & - \\
CNF & 0.6 & 30000 & - \\
FDC & 0.6 & - & 3 \\
\hline
\end{tabular}

is rather small in summer and in regions with a thin, broken ice cover.

The buoy data obtained by the International Arctic Buoy Program (IABP) [e.g., Colony and Rigor, 1995] are used as verification data. Over 100,000 daily buoy velocities spread over the Arctic were recorded in the period 1979-1994. Model velocities were interpolated onto the buoy positions to facilitate comparison with observations. The total mean of observed monthly buoy-drift speeds $\left(3.65 \mathrm{~cm} \mathrm{~s}^{-1}\right)$ is compared with the corresponding total mean of simulated drift speeds. The best values for $c_{a} / c_{w}$ are found through sensitivity runs, whereby the ocean drag coefficient was held constant $\left(c_{w}=5.5 \times 10^{-3}\right)$. Figure $4 \mathrm{a}$ shows the almost linear dependence of mean drift speed on the ratio of drag coefficients for the viscous-plastic model. The other models behave similarly. Optimal values of ratios $c_{a} / c_{w}$ for the individual models are given in Table 1.

The free-drift model with correction and the compressible Newtonian fluid have unrealistically low drift speeds. It was felt that it would not make sense to compensate this error with an unrealistically high ratio of drag coefficients. Therefore the ratios are limited to a maximum value of 0.6 for these investigations (Table 1 ). Note that the parameter values presented here are not universally valid. The ratios depend not only on the model physics but also on the forcing data used. The identical optimization procedure for the same models but forced with wind data from ECMWF give systematically smaller values. However, the relations of the values in the model hierarchy are the same [Kreyscher et al., 1997].

A question is whether the optimization with regard to monthly drift speeds provides also realistic mean drift speeds on other timescales. Therefore a comparison of drift speed was carried out for continuously increasing averaging periods of drift velocities (Figure 5). As expected, the total mean drift speed decreases with increasing averaging period [Harder and Fischer, 1999]. This is due to a high temporal variability of the direction of wind forcing, which tends to cancel out over larger averaging times. The mean drift speeds for the VPM and the CFM are optimized almost perfectly for timescales up to 50 days. The CNF and the FDC underestimate the mean drift speed despite using the highest tolerated ratio of drag coefficients (Table 1). The optimization is nearly independent of the timescale. This means that drift speed in climate models could be optimized by daily means also.
Besides the atmospheric and oceanic forcing the internal ice forces have a great impact on sea ice drift. This impact is determined by the rheology scheme and the strength parameterization (equation (10)). The central parameter in the latter is the large-scale ice-strength parameter $P^{*}$, which is not directly measurable.

The effects of ice interactions are well reflected in drift speed statistics [Colony and Thorndike, 1984; Ip, 1993; Lemke et al., 1997]. Therefore $P^{*}$ (or $h_{\max }$ for the FDC) is optimized with respect to speed distribution histograms in a second optimization step. Speed distributions of the models and the observations are calculated for four seasons and four disjunct regions covering the whole Arctic, each containing about 25,000 daily buoy velocities (for details see section 5.3). For each model, $P^{*}$ (or $h_{\max }$ ) is varied systematically, resulting in optimal parameter values for which the difference between observed and modeled speed histograms, as measured by the $\chi^{2}$ statistics, is minimized. Figure $4 \mathrm{~b}$ shows the results of these sensitivity runs for the VPM. The VPM shows a distinct minimum in mean $\chi^{2}-$ values for a value of $P^{*}=15,000 \mathrm{~N} \mathrm{~m}^{-2}$. In contrast to the VPM and the CNF the drift statistics of the CFM and the FDC are insensitive to variations in $P^{*}$ or $h_{\max }$. We obtain reasonable ice thickness results by using a value of $P^{*}=27,500 \mathrm{~N} \mathrm{~m}^{-2}$ for the CFM following Flato and Hibler [1992], and a value of $h_{\max }=3 \mathrm{~m}$ for the FDC. The optimal parameter values for all models are given in Table 1.

\subsection{Computational Efficiency}

The computational efficiency is an important aspect for the implementation of the different dynamics schemes in climate models. The CPU time consumed for a whole model run (not including output) was obtained for each model. Simulations were performed on a Cray-C916/16 computer system.

To examine, to a limited degree, the effects of vectorization, two sets of experiments were accomplished. In one series the vectorization option of the FORTRAN 77 compiler was set, and in the other, vectorization was

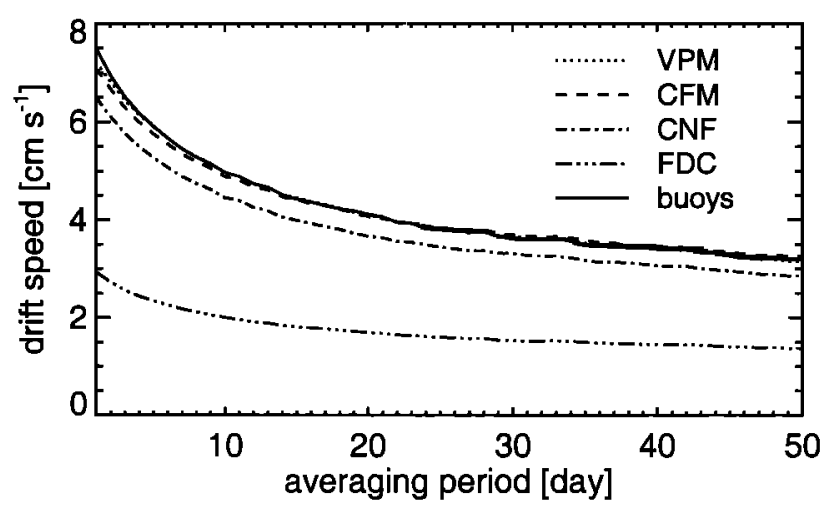

Figure 5. Total mean drift speed of simulated ice drift and corresponding buoy drift for different averaging periods. 
Table 2. Computer Time Used by Models

\begin{tabular}{lrrrr}
\hline Vectorization & VPM & CFM & CNF & FDC \\
\hline Yes & 260 & 510 & 110 & 50 \\
No & 1500 & 870 & 500 & 210 \\
\hline
\end{tabular}

Values are mean CPU time in $10^{-6} \mathrm{~s}$ per time step and grid point.

disabled. The results are shown in Table 2. The amount of CPU time consumed represents the degree to which the compiler vectorizes the codes and hence may not represent the maximum efficiency possible.

For pure serial simulations (no vectorization) the results show that the VPM uses the most computer time, being 7 times slower than the FDC. With vectorization enabled, the CFM needs significantly more CPU time than the VPM, indicating that this simpler scheme (in its current implementation) is more efficient only for nonvector machines. Generally, the more complete the schemes the more computer time they consume.

Altogether, the interpretation of computer efficiencies has to be viewed with some caution, because none of the codes have been optimized with respect to computer efficiency. Zhang and Hibler [1997] recently introduced a much more efficient numerical scheme for solving the viscous-plastic approach. Also, Hunke and Dukowicz [1997] developed the elastic-viscous-plastic (EVP) rheology that runs fast on parallel machines. While the original implementation of Hunke and Dukowicz [1997] had some problems to obtain truly plastic flow, a modified version of the EVP model seems to perform significantly better (E. C. Hunke, personal communication, 1999).

From the view of global climate simulations the sea ice component can use a relatively long time step (several hours), and the grid has to cover only about $20 \%$ of the globe. Further, sea ice is modeled as one layer, whereas the atmosphere and the ocean model components consist of a number of layers. This leads to minor computer time consumption of the sea ice component in comparison with the other components of the simulation, regardless of which ice rheology scheme is used.

\section{Ice Thickness}

Temporal and spatial variations in the thickness of Arctic sea ice are of significance in a variety of scientific problems. The importance of sea ice thickness for climate sensitivity, especially in the Northern Hemisphere, is demonstrated, e. g., by Rind et al. [1997]. Sea ice reduces the vertical heat, mass, and momentum exchange between the ocean and the atmosphere. Together with the ice drift, the ice thickness determines the horizontal ice-mass transport (representing a freshwater flux), which influences the freshwater budget of the Arctic Ocean and the North Atlantic markedly [e. g., Aagaard and Carmack, 1989; Harder et al., 1998]. The strength of the sea ice cover, which limits the maximum internal ice stress, is dictated by the ice thickness distribution [Thorndike et al., 1975]. Furthermore, the ice thickness might be an important indicator for climate trends, because it integrates the thermodynamic and dynamic effects of ocean and atmosphere over long time periods.

\subsection{Observational Ice Thickness Data}

Measurements of the spatial-temporal distribution of ice thickness are limited. A variety of technologies have been applied to observe ice thickness. These include drill hole measurements [e.g., Eicken et al., 1995], imaging sensors on aircraft or satellite providing information only on thin ice [Groves and Stringer, 1991], laser profilometer used from aircraft [e.g., Lewis et al., 1993], and electromagnetic methods [Kovacs and Holladay, 1989]. None of these technologies has yet yielded a comprehensive data set on ice thicknesses in the Arctic for a number of regions or covered a complete seasonal cycle at one location.

From below the ice, upward looking sonars (ULS) mounted on submarines have been used for several decades to determine the draft and ridging characteristics of sea ice in the Arctic Ocean. These data sets, obtained from military operations, are now partly declassified and are becoming publicly available to a limited extent. Also, ice thickness data from a few scientific submarine cruises (Scientific Ice Expeditions (SCICEX) program) are now becoming published [e. g., Rothrock et al., 1999].

Moorings offer an alternative to submarines for observations of underside sea ice topography, year-round

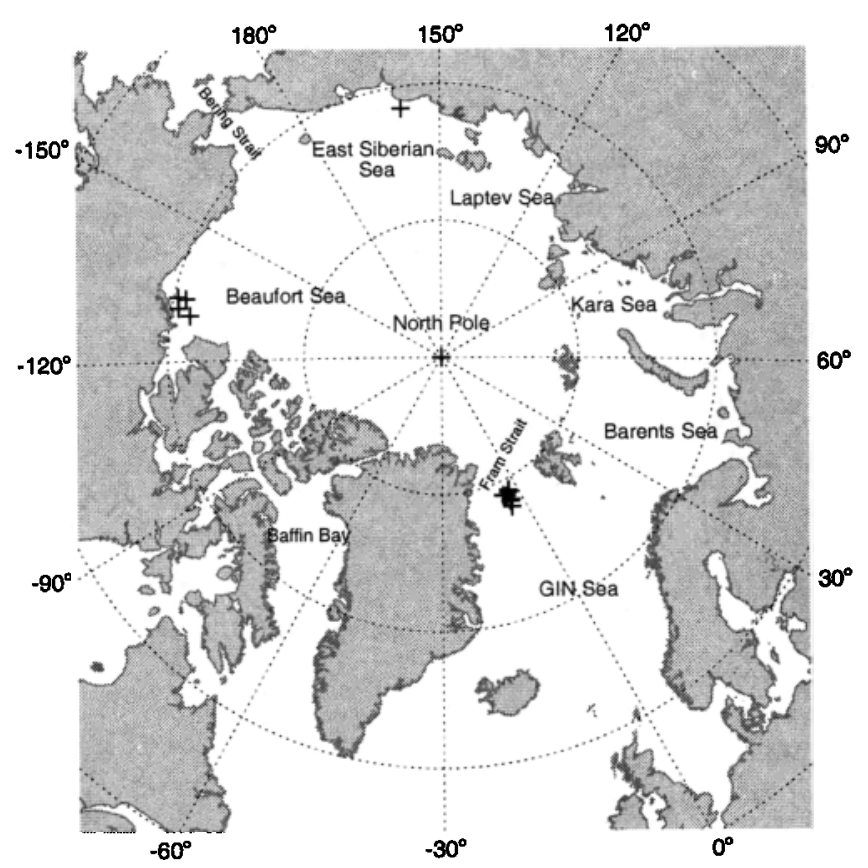

Figure 6. Positions of ice thickness observations from moored and submarine upward looking sonars used for model verification (see text for data references). 

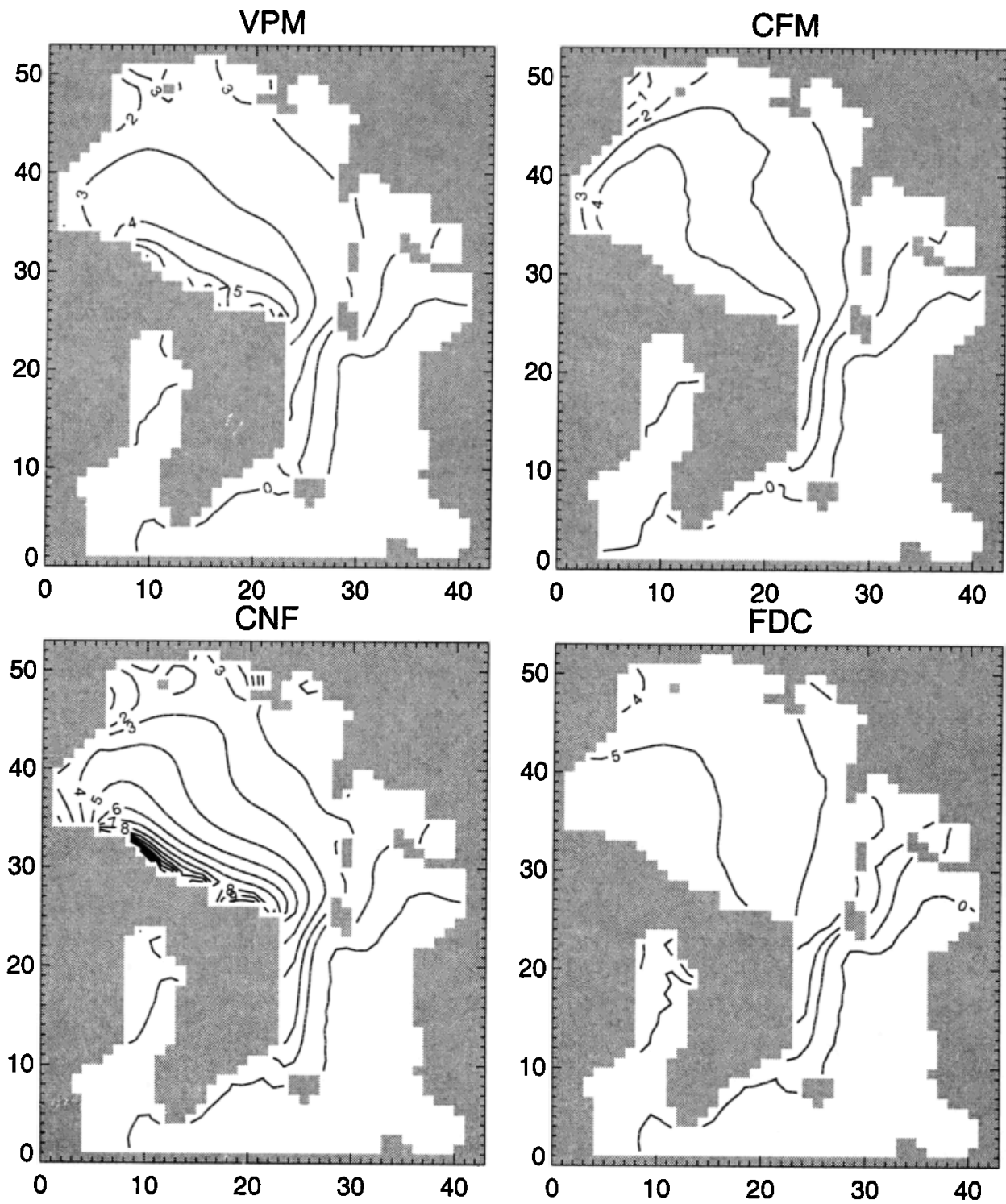

Figure 7. Mean spatial pattern of ice thickness (m) for March of the years 1979-1995.

at one location and regardless of water depth. Moored sonars have been deployed in the Arctic since 1987 [e.g., Melling and Riedel, 1996; Vinje et al., 1998].

Ice thickness measurements used for model validation in this paper are obtained from upward looking sonars on both submarines and moorings. Submarine-derived measurements are available for the North Pole, during the period 1979-1992, from cruises that crossed the pole [McLaren et al., 1994]. Eight mean ice draft values, based on $100 \mathrm{~km}$ long segments centered over the pole, are available. Wadhams [1997] estimates the statistical error of these data to be about $10 \%$. The conversion ratio from ice draft to ice thickness has an additional uncertainty of about $10 \%$.

A second data source is the measurements from ULS on oceanographic moorings. There are data available from the Fram Strait (91 monthly means during 19901994 [Vinje et al., 1998]), East Siberian Sea (13 monthly means from 1988 to 1989 [Moritz, 1990]), and nearshore Beaufort Sea (122 monthly means during 1990-1995 [Melling and Riedel, 1996]). In addition to the conversion uncertainty, there is a systematic error of the moored ULS draft data estimated to be up to $25 \mathrm{~cm}$ [Moritz, 1990]. Figure 6 gives an overview of the locations where ice thickness data are obtained.

\subsection{Spatial Pattern of Ice Thickness}

The mean spatial pattern of ice thickness in March for the time period 1979-1995 is calculated to reveal the impact of the different sea ice rheologies on the simulated ice thickness (Figure 7). The VPM predicts mean ice thicknesses in the central Arctic of about 3-4 m increasing off the Canadian archipelago to maximum values of 7-8 m. The thickness in this region results from the Beaufort gyre circulation (see Figure 13) tending to pile up ice near the Canadian coast. This behavior 


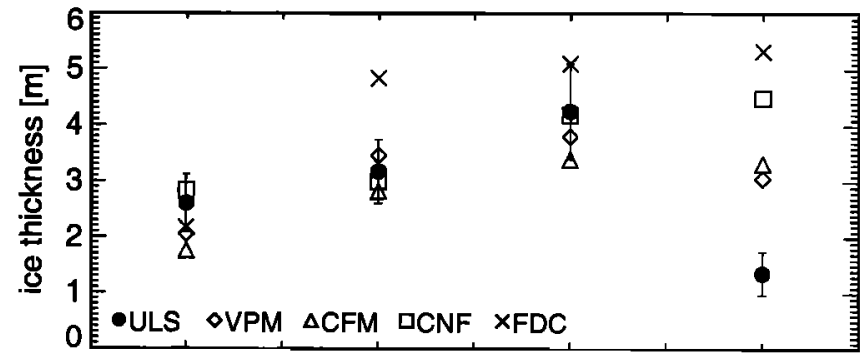

Fram Strait East Siberian North Pole Beaufort Sea

Figure 8. Mean ice thicknesses at upward looking sonar (ULS) positions for all models and the observations (see text for data sources).

is consistent with long-term-averaged submarine ULS observations [Bourke and McLaren, 1992].

In contrast, the CFM yields the maximum ice thickness farther west in the Beaufort Sea. Because of the neglect of shear strength in this scheme, sea ice slips easily parallel to the coast and drifts into the Beaufort Sea.

The CNF produces a thickness pattern similar to the VPM but has much larger ice thicknesses near the Canadian coast with values up to $15 \mathrm{~m}$. Obviously, the linearviscous medium is not able to prevent an excessive ice thickness buildup in regions with mainly convergent ice drift.

The FDC shows a relatively uniform ice thickness with systematically higher values than the other models.

Altogether, the differences between the models are quite obvious and have a physical explanation. This raises the question if these differences can be detected quantitatively by comparing the simulation results with the ULS observations. Therefore simulated ice thicknesses are interpolated onto the ULS positions, and the overall 234 monthly means are compared with the corresponding observational data.

Figure 8 shows total mean ice thicknesses for the different regions. The VPM, the CFM, and the CNF predict reasonable mean ice thicknesses in the Fram Strait, the East Siberian Sea, and at the North Pole. Only the FDC produces significantly high ice thicknesses in the latter two regions. Noticeable are the data for the Beaufort Sea. All models simulate ice thicknesses much too large in this region, although the VPM and CFM are markedly better than the other two models. A reason may be that the ULS locations in that region are extremely close to the coast. Topography or coastline effects are not well-resolved by the large-scale models.

There are many data available for the Fram Strait and the Beaufort Sea to investigate the interannual variability of ice thickness. Figures $9 \mathrm{a}$ and $9 \mathrm{~b}$ show the time series of annual ice thickness anomalies in these regions. During the period 1990-1994 the ice thickness in Fram Strait continously increased about $0.4 \mathrm{~m} / \mathrm{yr}$. All models are able to reproduce this long-term positive trend and simulate similar anomaly time series. Observed ice
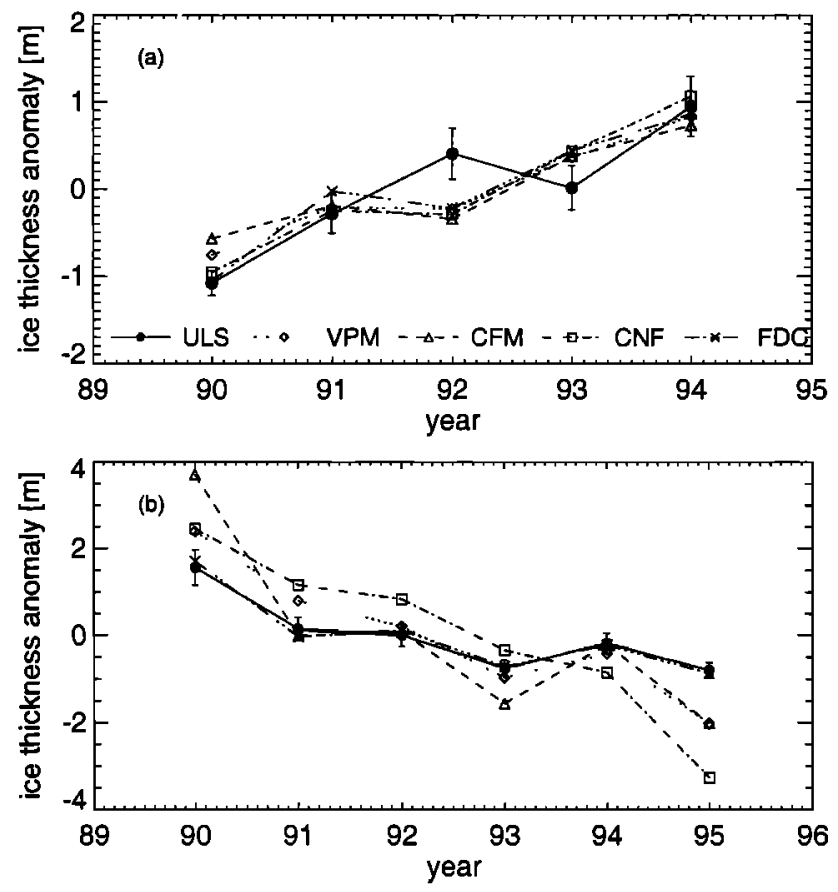

Figure 9. Time series of anomalies of annual mean ice thicknesses for (a) Fram Strait and (b) Beaufort Sea (see text for data references).

thickness in the Beaufort Sea region has a pronounced negative trend for the years 1990-1995 with about the same magnitude as in Fram Strait. Again, all models are capable to reproduce this negative trend.

Root-mean-square (RMS) errors for the spatial pattern of ice thickness (Figure 8) and the ice thickness anomaly time series (Figures $9 \mathrm{a}$ and $9 \mathrm{~b}$ ) are summarized in Table 3 . The quantitative comparison confirms the results shown above and reveals clear differences in the spatial ice thickness distributions. The VPM yields the smallest RMS errors followed by the CFM and CNF. The FDC has relatively large RMS errors due to systematically overestimated ice thickness.

Differences in annual anomalies are much smaller between the models in the hierarchy. For the Fram Strait region, there are no marked differences. In the Beaufort Sea the FDC yields by far the smallest RMS error with respect to this diagnostic, while the VPM as the second-best model shows a much larger error. Thus the FDC performs best with respect to ice thickness anomalies in the Beaufort Sea but at the cost of an un-

Table 3. RMS Errors in Meters for the Spatial Pattern of Ice Thickness (Figure 8) and Annual Anomalies of Ice Thickness in Fram Strait and Beaufort Sea (Figures 9a and $9 \mathrm{~b}$ )

\begin{tabular}{lcccc}
\hline & VPM & CFM & CNF & FDC \\
\hline Spatial pattern & 0.9 & 1.2 & 1.6 & 2.2 \\
Anomalies in Fram Strait & 0.3 & 0.4 & 0.3 & 0.3 \\
Anomalies in Beaufort Sea & 0.8 & 1.2 & 1.4 & 0.1 \\
\hline
\end{tabular}

RMS, root-mean-square. 


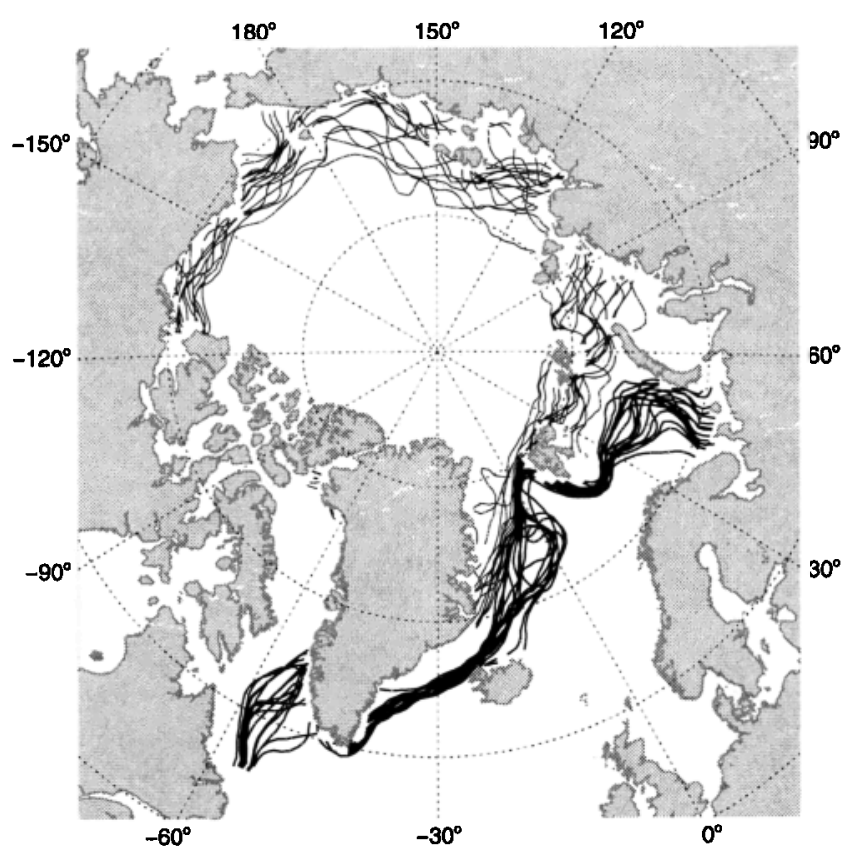

Figure 10. Summer (thin line) and winter (thick line) ice extent for the years 1979-1995.

realistically high mean ice thickness, whereas the VPM gets the mean ice thickness better but has difficulties to reproduce the anomalies. This unsatisfactory result is not yet fully understood; however, it is very well possible that insufficiencies in the forcing fields or in the simple thermodynamic code are responsible.

\section{Ice Extent}

Sea ice extent of the Arctic varies between a minimum of $7 \times 10^{6} \mathrm{~km}^{2}$ in September and a maximum extent of $15 \times 10^{6} \mathrm{~km}^{2}$ in March [Gloerson and Campbell, 1992]. In addition to the pronounced seasonal cycle, there is a large interannual varibility observed (Figure 10). The question is how the different sea ice rheologies influence the simulated ice extent or, more generally, how useful observed sea ice extent time series are for the validation of sea ice rheologies.

\subsection{Observational Ice Extent Data}

For our study, ice concentration data from passive microwave radiometers for the period 1979-1995 are used. Monthly mean ice concentrations are computed from daily fields derived from Defense Meterological Satellite Program (DMSP) scanning multichannel microwave radiometer (SMMR) and Special Sensor Microwave Imager (SSM/I) [Weaver et al., 1987]. Both data sets are obtained from the National Snow and Ice Data Center and are calculated using the NASA team algorithm [Cavalieri et al., 1984]. The land mask was enlarged to cover $50 \mathrm{~km}$ of adjacent ocean to eliminate the spurious ice concentration data for coastal ocean pixels [Maslanik et al., 1996; Serreze et al., 1995]. Subsequently, the ice concentration fields $(25 \mathrm{~km} \times 25 \mathrm{~km}$ resolution) were averaged onto the model grid $(110 \mathrm{~km} \times 110 \mathrm{~km}$ resolution) by averaging all satellite data within a $55 \mathrm{~km}$ distance from the model grid points.

Figure 10 shows the observed summer (September) and winter (March) ice extents for all simulated years (1979-1995). There is a marked interannual variability for the summer ice extent at almost all longitudes, whereas the winter ice extent varies most in the Barents Sea, the Labrador Sea, and the eastern Greenland Sea. A sea ice tongue, the so-called "Odden," occurs in irregular intervals in the eastern Greenland Sea. Remarkable also is the region west of Spitsbergen where no seasonal or interannual variations of the ice cover are observed. This region is strongly influenced by a warm coastal current west of Spitsbergen and a continous outflow of sea ice from the central Arctic through Fram Strait. This region is the most northerly area that is ice-free throughout the whole year.

\subsection{Anomalies of Sea Ice Extent}

To compare the seasonal and interannual variability of the simulations and the observations quantitatively, the anomalies of the monthly sea ice extent series are calculated. For the analysis data from the Arctic Ocean and peripheral seas, the Barents Sea and the GIN Sea are considered, whereas no data from the Labrador Sea and the Bering Sea are included (analogous to the investigations of Maslanik et al. [1996] and Serreze et al. [1995]). We define the ice extent as the area of grid cells having at least $15 \%$ ice concentration. The radial gap in SMMR and SSM/I orbit coverage near the pole (north of $84^{\circ} \mathrm{N}$ ) is treated as completely ice covered. Comiso et al. [1997] estimate the relative error of observed ice extent as less than $3 \%$.

Figure 11 shows the time series of sea ice extent anomalies for the summer (September) and winter (March) situations. An observed summer sea ice extent shows a marked interannual variability with a standard deviation $\sigma=0.4 \times 10^{6} \mathrm{~km}^{2}$. Large variations from year to year are found especially during the period 19881995. The years 1990 and 1995 are characterized by record minima in the Arctic sea ice extent [Maslanik et al., 1996; Serreze et al., 1995]. Two of the models, the VPM and the CNF, are able to reproduce these minima with nearly the observed amplitude, whereas the two other models underestimate the amplitude of the anomalies.

For the first 3 years (1979-1981) the simulation results of all four models show a large discrepancy to the satellite data in September. Because the differences among the results of the four models are small compared to their general deviation from the SSM/I data, this is unlikely to be caused by effects of rheology. We suspect that either the satellite data or the forcing fields are inaccurate in these early years, but we have not been able to prove any of these possible reasons. 

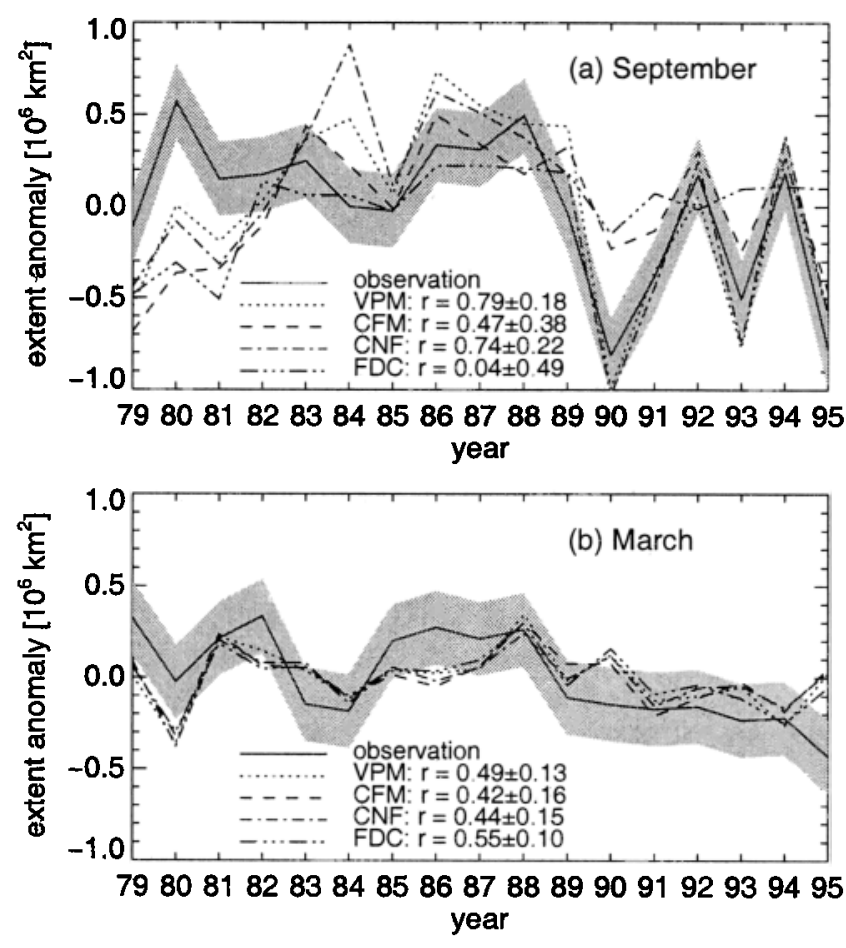

Figure 11. Anomalies of ice extent: (a) September, (b) March; $r$ gives the correlation coefficient between simulation and observation. The shaded range shows the estimated error of the observation.

The quantitative analysis is based on correlation coefficients for the simulated and observed time series (Figure 11). The range of individual correlation values is calculated for a confidence interval of $95 \%$. The correlation coefficients for the VPM and the CNF are highest, reflecting the capability of reproducing the strong variability since 1988 . The CFM yields a smaller correlation. The FDC has a correlation value of nearly zero and performs worst with respect to the summer ice extent anomalies.

The results are different for the ice extent anomalies in winter. First, the variability is much smaller than in summer $\left(\sigma=0.23 \times 10^{6} \mathrm{~km}^{2}\right)$. Second, all models predict very similar winter ice extent anomalies. This is reflected by correlation coefficients that are close together, thus not allowing to distinguish the performance of the models.

All correlation values for the winter data are on a relatively low level. One reason is that the models are not able to predict the slight negative trend in the observed extent time series $\left(-0.03 \times 10^{6} \mathrm{~km}^{2} / \mathrm{yr}\right)$. This is presumably due to the climatological oceanic heat forcing that contains no interannual variability or trend.

Altogether, the winter sea ice extent reveals only small differences between the sea ice rheologies. In contrast, the summer sea ice extent is significantly influenced by the different rheology approaches and should be considered for investigations on sea ice dynamics.

\section{Ice Drift}

The sea ice cover is generally in motion. More than $70 \%$ of the short-term variance of the ice velocity is explained by atmospheric forcing, whereas long-term drift patterns reflect roughly equal contributions by winds and surface currents [Thorndike and Colony, 1982].

In addition to the atmospheric and oceanic forcing, internal ice stresses have a marked impact on the ice drift within about $400 \mathrm{~km}$ near the coasts [Thorndike and Colony, 1982]. In extreme cases the sea ice is attached to the shoreline by strong internal ice stresses forcing the pack to block up and stand still (so-called landfast ice). This slowdown is strongest in wintertime where the ice cover is most compact and internal forces are largest. In summer, the opening of leads decreases the interactions between ice flows, and therefore the internal ice stresses are weaker.

Here we present the comparison of observed and simulated ice drift for timescales of days to months. Further, the statistics of drift speeds are investigated for different seasons and regions of the Arctic. This answers the following questions: Which rheology scheme predicts the most realistic ice drift? How does the validation of sea ice rheologies depend on the applied timescale, region, and error function?

\subsection{Observational Drift Data}

Two independent data sources are used as verification data. First, more than 100,000 daily drift buoy velocities are available during the period 1979-1994 which

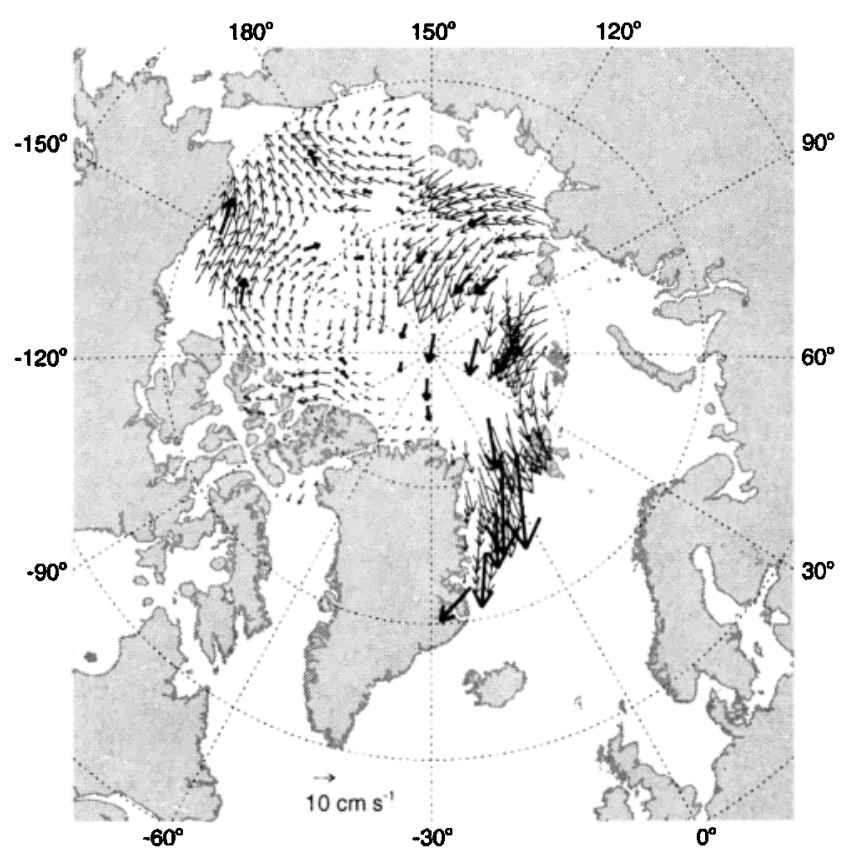

Figure 12. Drift field derived from Special Sensor Microwave/Imager (SSM/I) observations (thin arrows) for October 4-6, 1994 [Martin and Augstein, 1998], and corresponding buoy velocities (thick arrows) from International Arctic Buoy Program (IABP) data. 


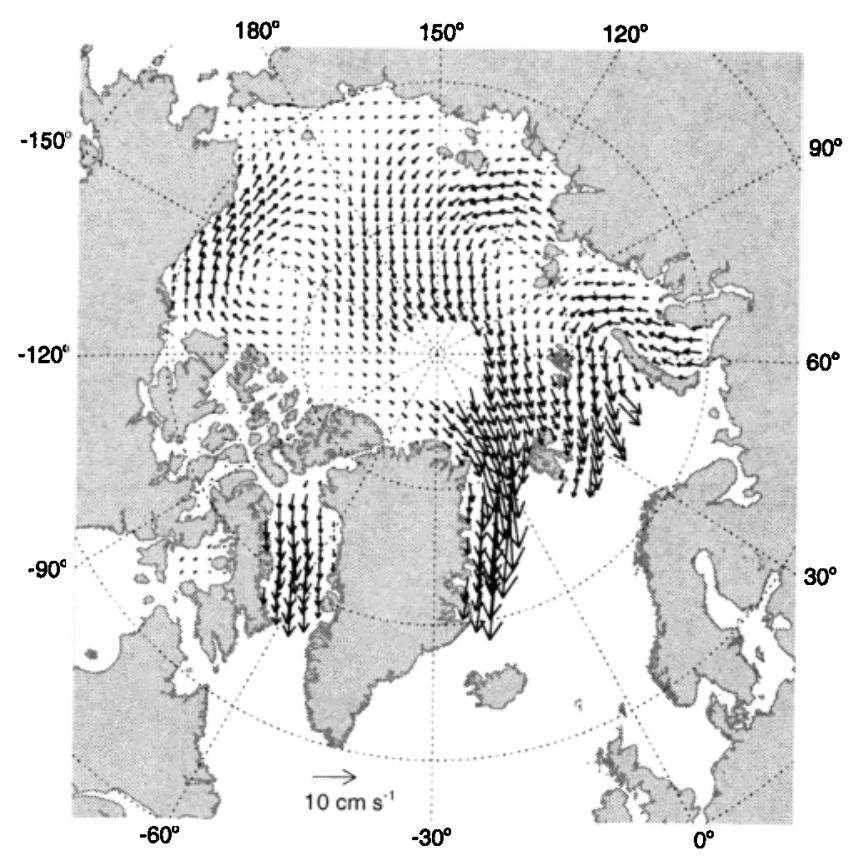

Figure 13. Mean ice drift of winters $1987 / 1988$ and 1994/1995, derived from SSM/I data [Martin and Augstein, 1998]. Vectors are shown only for regions with more than $70 \%$ temporal data coverage.

cover the Arctic basin. The buoy velocities are calculated from daily buoy positions obtained from the International Arctic Buoy Programme (IABP) [e.g., Colony and Rigor, 1995].

Second, large-scale sea ice drift fields retrieved from passive microwave satellite data are used. A recently developed method using the $85.5 \mathrm{GHz} \mathrm{SSM} / \mathrm{I}$ data [Agnew et al., 1997; Kwok et al., 1998; Martin and Augstein, 2000] determines the large-scale ice drift for timescales of 3 days and longer. The satellite-derived mean drift speed and the variability of the ice drift correspond closely with drifting-buoy data (Figure 12). Absolute errors of the 3 day ice-drift velocities are estimated to be smaller than $1 \mathrm{~cm} \mathrm{~s}^{-1}$ [Martin and Augstein, 2000]. The advantage of the satellite-derived drift data is that they cover almost the entire Arctic, whereas there are only a few buoy observations spread over the Arctic region within a 3 day period.

The satellite-retrieved data available for our investigations cover the winter periods (October-March) of $1987 / 1988$ and $1994 / 1995$. Only winter data are obtained because water vapor and clouds disturb the tracking algorithm in summer. The data set contains more than 300 three day velocity fields for the two winters. Mean averaged ice drift for these two winters is shown in Figure 13.

Two features dominate the mean large-scale drift pattern. The Beaufort gyre drives the sea ice in a clockwise (anticyclonic) motion out of the Beaufort Sea along the Siberian coast and merges into the Transpolar Drift Stream (TPDS), moving the pack ice across the cen- tral Arctic. A large amount of sea ice leaves the Arctic Ocean through Fram Strait and melts in the Greenland/Iceland/Norwegian (GIN) Seas. A detailed investigation of the Fram Strait ice export, predicted by the different rheology schemes, is shown in section 6 .

The simulated mean drift fields are calculated for the time periods when observation data are available. Figure 14 shows the mean drift pattern for the four models. Differences between the models in the hierarchy are visible. Because of the neglect of shear strength, a marked increase in drift speed parallel to the northern coast of Greenland and in the narrow Bering Strait is visible for the CFM. The CNF simulates significantly smaller drift speeds in Fram Strait and Bering Strait. The linear-viscous behavior slows down the velocities too much. The FDC has much too small ice-drift velocities in the whole Arctic region caused by the crude velocity correction scheme.

\subsection{Ice Drift for Different Averaging Periods}

The quantitative comparison of simulated and observed ice drift is accomplished for a range of timescales. Progressive vector plots are calculated from the daily buoy velocities to obtain drift information for time periods longer than 1 day. This approach [Flato and Hibler, 1992; Ip, 1993; Geiger et al., 1998] adds vectorially the drift vectors calculated from simulated velocity fields at each point of the observed buoy-drift track. This is in contrast to simulated particle trajectories where drift vectors are calculated at the simulated particel locations [Harder, 1997; Harder and Fischer, 1999]. The advantage of the progressive vector plot method is that errors in the predicted ice drift at a few locations do not necessarily disturb the entire comparison. To perform progressive vector plot calculations, it is necessary that the observed buoy trajectories have no gaps. This limits the possible averaging period to about 50 days at maximum. There are not enough buoy drift tracks without gaps available for longer timescales.

Averaging of drift velocities is simpler for the SSM/Iderived ice drift fields. First, the satellite data with a spatial resolution of $25 \mathrm{~km}$ are merged onto the model grid. Temporally correspondent, 3 day mean model velocities are then calculated for all satellite data locations. This leads to spatially and temporally correspondent simulation and observation data sets. Finally, drift velocities at each grid point are averaged for systematically increasing time periods. The number of available satellite data marks the limit of 308 days averaging period, which is much longer than the maximum buoydrift averaging period.

To measure the performance of the different models, correlation coefficients are calculated by considering both horizontal components of the simulated and observed ice drift velocities. All available data, i.e., over 400,000 velocity components from the buoy and satellite observations, are used for the calculation. Be- 

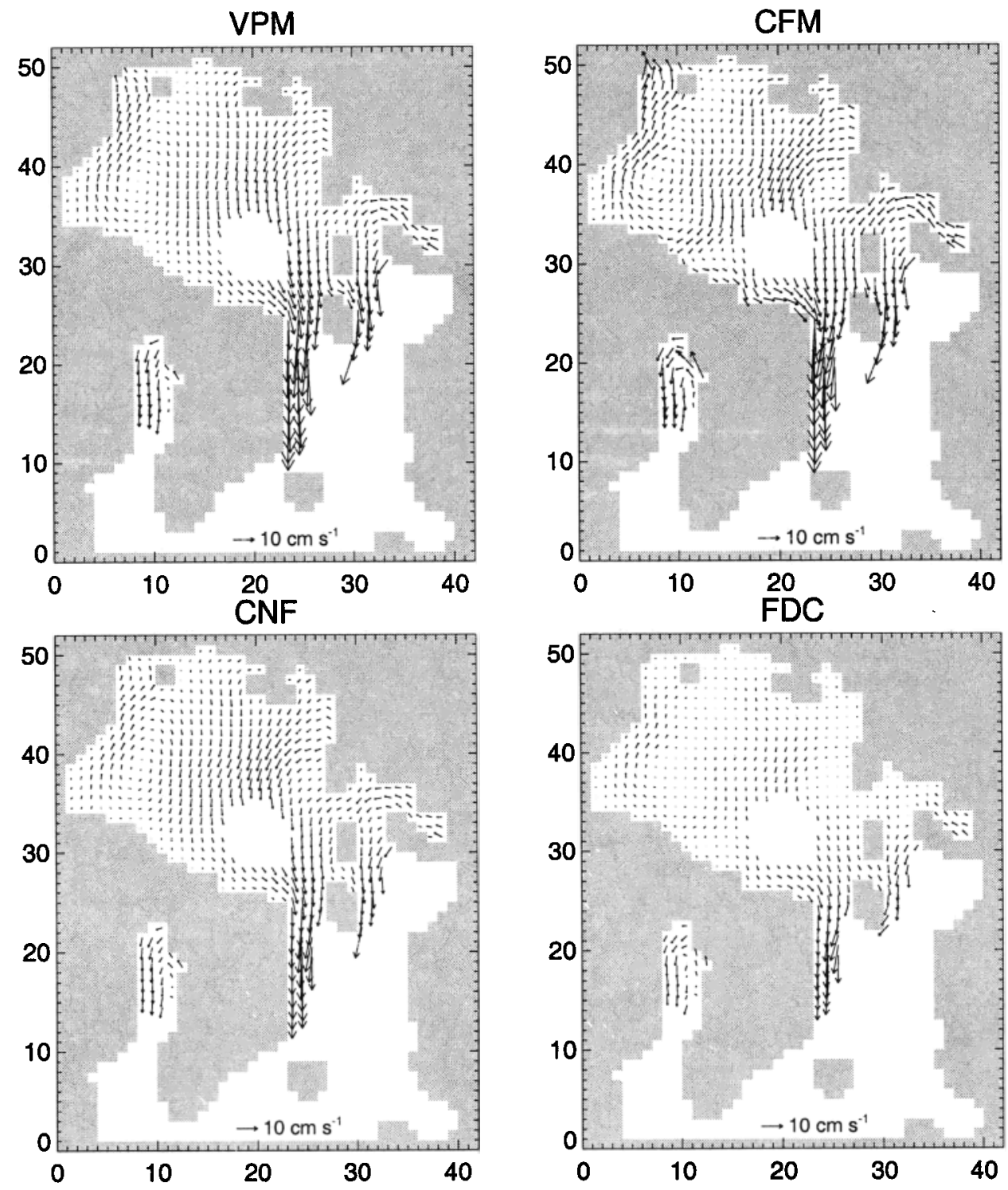

Figure 14. Mean simulated drift fields of winters $1987 / 1988$ und $1994 / 1995$, analogous to SSM/I-observed drift fields (Figure 13).

cause of the large number of data, differences between the models are statistically highly significant.

Progression of the correlation coefficients with increasing averaging period is prominent for all models (Figure 15). There is an abrupt rise in all curves for averaging periods longer than a few days. This is caused by the fact that both observation data and forcing fields have highest errors for short timescales. The error of the buoy data depends on the quality of the location measurement. For longer drift periods the distances between start and end points of the trajectories increase, and therefore the relative location errors decrease [e.g., Harder and Fischer, 1999]. The quality of the SSM/Iderived drift fields increases also for longer time periods because outliers of the tracking algorithm get smoothed through averaging.
The comparison between the models shows distinct differences. The VPM yields the best results for all averaging periods. In contrast, the FDC has the lowest correlation coefficients in all cases. An interesting behavior can be seen for the CFM in comparison with buoy drift (Figure 15). While all other models show increasing correlation coefficients with increasing averaging periods, the CFM reaches a maximum after about 10 days and falls behind the CNF for time periods longer than a few days. The absence of shear strength reduces the quality of results, especially on longer timescales. This shows how the evaluation of sea ice rheology schemes depends on the timescale over which the velocities are averaged.

Results based on the two different data sources (buoy data Figure 15a and SSM/I data Figure 15b) are slightly 

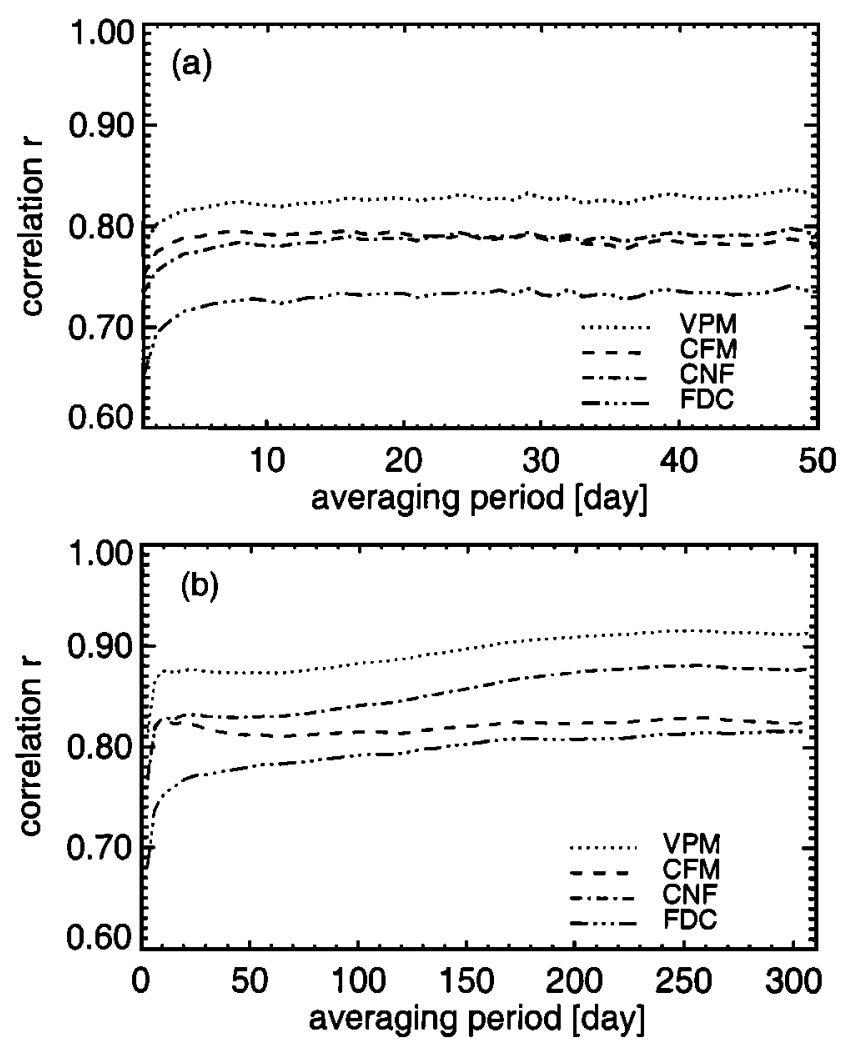

Figure 15. Correlation between simulated and observed ice drift for different averaging periods: (a) drifting buoy, (b) satellite retrieved.

different. The differences are caused by the fact that the underlying data are distributed differently in space and time. The buoy data cover all seasons during the whole period 1979-1994 and have their highest density in the central Arctic and the Beaufort Sea. There are only few buoy data available for the Siberian shelf areas. In contrast, the SSM/I-derived data cover only the wintertime (October-March) of 2 years but with a nearly uniform spatial distribution. Both data sets show qualitatively the same progression of the curves and identify the VPM clearly as the model with the best results in this hierarchy.

\subsection{Drift Speed Statistics}

An additional method to examine the effects of different sea ice rheologies is the comparison of simulated and observed ice drift statistics [Ip, 1993; Lemke et al., 1997; Kreyscher et al., 1997]. The calculation of drift statistics is based on the daily drifting-buoy velocities of the IABP. Model results are interpolated onto the buoy positions for an appropriate comparison. Only spatially and temporally correspondent velocities are compared.

Histograms of daily drift speed for the simulations and the observations are calculated (Figures 16 and 17). Speed distributions are calculated for four seasons (January-March, April-June, July-September, and Oc-
tober-December), containing data from the whole Arctic. Additionally, histograms are calculated for four separate regions: Fram Strait $\left(60^{\circ} \mathrm{O}-30^{\circ} \mathrm{W}\right)$, Canada $\left(30^{\circ} \mathrm{W}-120^{\circ} \mathrm{W}\right)$, Beaufort Sea $\left(120^{\circ} \mathrm{W}-150^{\circ} \mathrm{O}\right)$, and Siberian shelf areas $\left(150^{\circ} \mathrm{O}-60^{\circ} \mathrm{O}\right)$. This describes the spatial and temporal variance of the model performances. Each histogram contains about 25,000 daily buoy velocities.

Values of $\chi^{2}$ for the different histograms are calculated for a quantitative comparison of simulated and observed statistics [Ip, 1993]. High $\chi^{2}$-values indicate large differences between the simulated and the observed distributions.

The speed distributions for the drifting buoys are all characterized by a distinctive peak near the origin, indicating a large fraction of drift speeds below $1 \mathrm{~cm} \mathrm{~s}^{-1}$, which we call "stoppage" (Figures 16 and 17). This fraction of drift speeds between zero and $1 \mathrm{~cm} \mathrm{~s}^{-1}$ varies markedly with the season (Figure 16). In winter, when the ice cover is most compact, the ice drift speed is below $1 \mathrm{~cm} \mathrm{~s}^{-1}$ for nearly $20 \%$ of the days. The fraction of drift stoppage decreases in the second quarter of the year and falls to $5 \%$ in summer. The ice cover in summer is influenced by melting processes leading to a loose ice pack with a large lead fraction. Therefore the interaction between the individual ice flows and the internal ice stresses are much weaker than in wintertime. Internal ice forces are then less able to slow down the ice drift. In fall the ice cover begins to close up, leading to a perceptible reduction of drift speeds due to increasing internal ice forces.

There are pronounced differences between the models in the hierarchy. The VPM shows a marked seasonal cycle in drift speed stoppage similar to the observations. However, the fraction of drift speeds smaller than $1 \mathrm{~cm} \mathrm{~s}^{-1}$ is underestimated in winter and slightly overestimated in summer.

In contrast to the VPM the CFM shows significant systematic differences compared with the observations. The CFM predicts much too small a seasonal cycle of drift stoppage and is not able to reproduce the large amount of small drift speeds. This is the main drawback of this rheology. Because of the neglect of shear strength the CFM is not able to simulate the slowing down of ice drift caused by internal shear stresses. The differences between the CFM and the observed speed distributions reveal the large impact of shear forces on the large-scale ice drift.

The CNF also simulates a very weak seasonal cycle of drift stoppage and underestimates the slow drift velocities in winter and spring systematically. Although the CNF incorporates shear strength, it is not able to force the sea ice to drift stoppage. This is due to the constant viscosities of the CNF. These are in contrast to the VPM, where the viscosities depend highly nonlinearly on the deformation rate. 

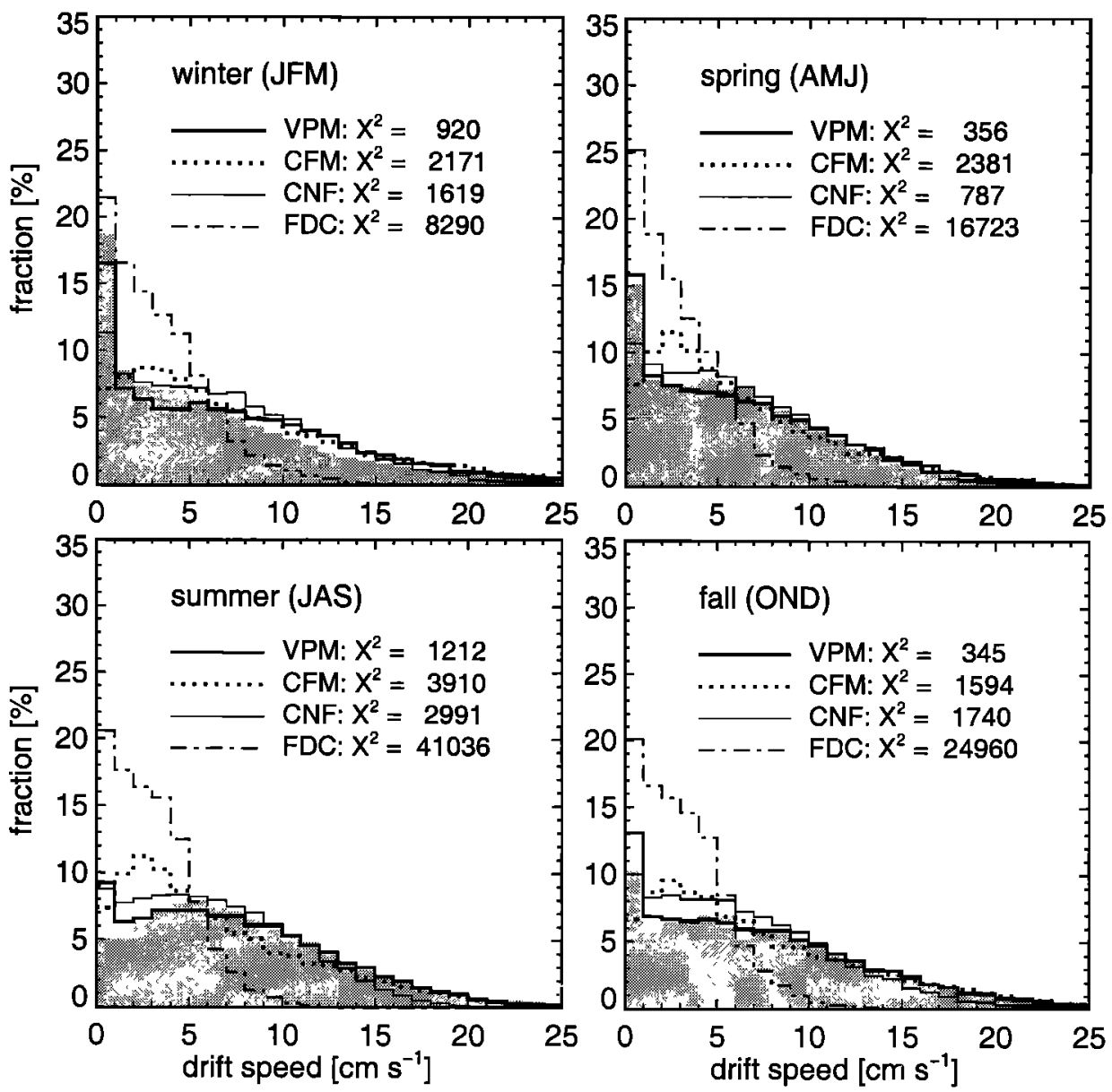

Figure 16. Statistics of observed daily buoy speed (shaded histograms) and statistics of corresponding simulated drift speeds (line histograms) for different seasons.

Unrealistic speed distributions are predicted by the FDC which systematically underestimates drift velocities. The correction of free drift velocities is applied in many cases and then sets one or both velocity components to zero. This results in an excessive damping of the velocity fields.

Speed distributions for different regions (Figure 17) can also be characterized by the amount of small drift velocities. Noticeable is the region north of Canada with a mean drift-stoppage fraction of over $30 \%$ for the whole year. The sea ice cover in this region is the most compact of the Arctic. The ice thickness buildup in that region is caused by a mainly convergent drift that leads to maximum mean ice thicknesses of about $8 \mathrm{~m}$ (see section 3.2). Therefore the impact of internal ice stresses on the ice drift is clearly visible in that region. The VPM, CNF, and FDC slightly overestimate the drift stoppage, whereas the CFM underestimates the small speeds north of Canada. The histograms of the other regions show less distinctive differences and reconfirm the deficiencies of the different rheology approaches discussed before.
The $\chi^{2}$-values for the histograms reveal the differences between the models quantitatively. For all speed distributions the VPM yields the best $\chi^{2}$-values. In contrast, the FDC simulates the most unrealistic speed statistics reflected in the highest $\chi^{2}$-values. CFM and CNF achieve similar, medium $\chi^{2}$-values, whereby the order changes from case to case.

\section{Fram Strait Sea Ice Export}

Fram Strait, confined by the coasts of Greenland and Spitsbergen, is of great importance for the mass and energy budget of the Arctic Ocean. Sea ice export through Fram Strait of the order of $0.1 \mathrm{~Sv}$ almost compensates the freshwater inflow of all rivers entering the Arctic Ocean [Aagaard and Carmack, 1989]. The ice export advects freshwater through Fram Strait into the Greenland/Iceland/Norwegian (GIN) Seas, a region having a great impact on the global conveyer belt. The ice export from the Arctic exhibits considerable interannual to decadal variability and is supposed to be the major cause for the so-called "great salinity anomaly" 

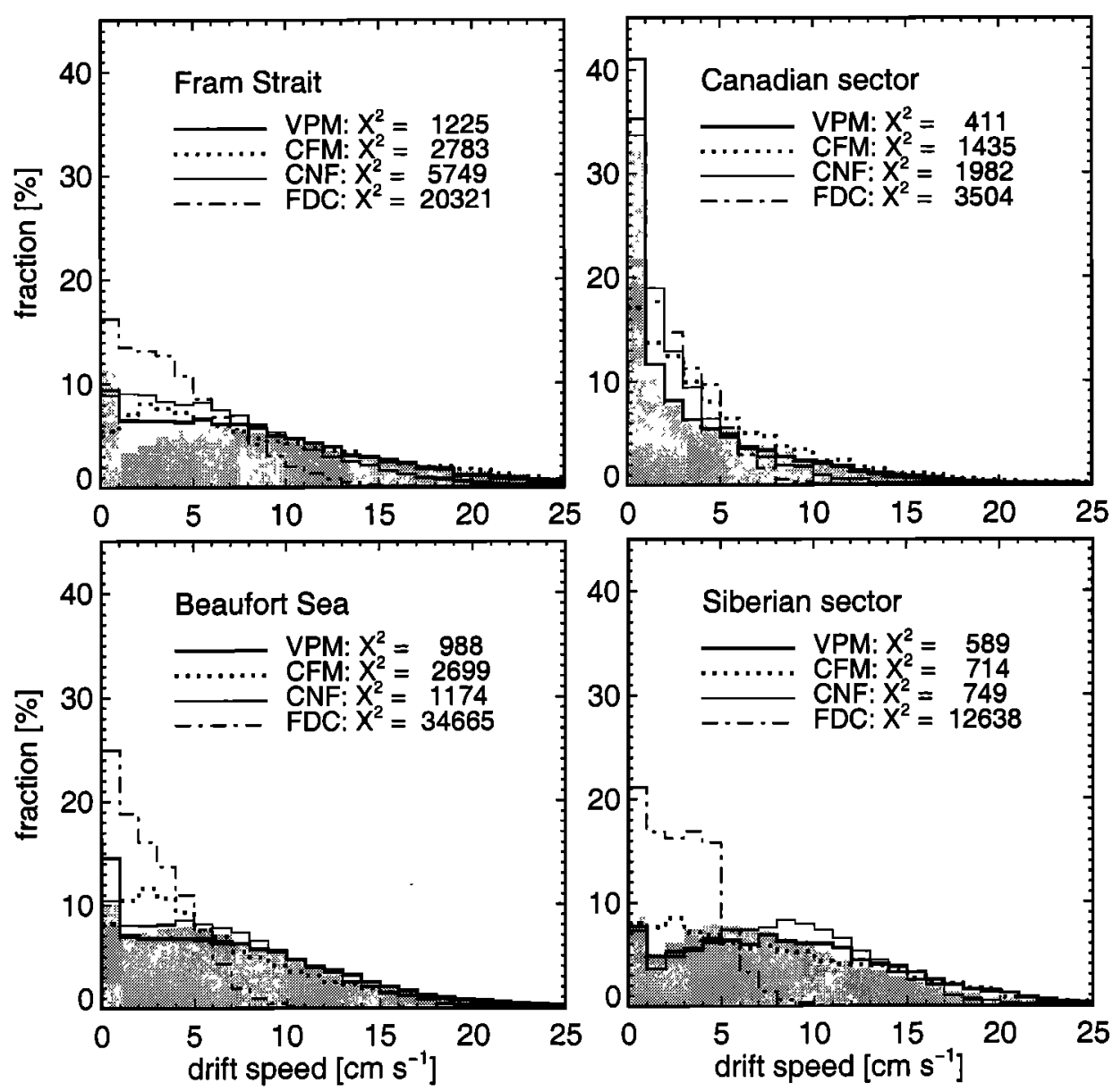

Figure 17. Statistics of observed daily buoy speeds (shaded histograms) and statistics of corresponding simulated drift speeds (line histograms) for different regions.

observed in the northern North Atlantic [Dickson et al., 1988; Aagaard and Carmack, 1989; Häkkinen, 1993; Harder et al., 1998; Hilmer et al., 1998].

For the evaluation of the simulated ice export through Fram Strait it is necessary to include observational data of both the ice drift and the ice thickness in Fram Strait. We discuss results of the comparison with SSM/I-derived ice drift fields and ULS ice thickness measurements in Fram Strait. It should be noted that none of the models is optimized specifically for the Fram Strait region. All models are optimized only with regard to the total mean drift speed and the daily drift speed histograms, as described in section 2.4 .

The SSM/I-derived drift fields are averaged across Fram Strait at $80^{\circ} \mathrm{N}$ (Figure 3). The corresponding time series of the model velocities are calculated. Figures $18 \mathrm{a}$ and $18 \mathrm{~b}$ show the time series of northward velocities for the observations and the VPM during the winters 1987/1988 and 1994/1995. A pronounced variability of the drift speed can be seen in the Fram Strait region. Mean ice drift speed is directed southward and reaches maximum drift speeds of $30 \mathrm{~cm} \mathrm{~s}^{-1}$ in winter. An import of sea ice into the Arctic occurs only in a few cases. The variability of drift speeds on the 3 day timescale is well-reproduced by the VPM (RMS error $=4.2 \mathrm{~cm} \mathrm{~s}^{-1}$ ).

Results for the different models are compared for monthly mean drift velocities (Figures $18 \mathrm{c}$ and 18d). The observed mean drift speed of $10.2 \mathrm{~cm} \mathrm{~s}^{-1}$ is best reproduced by the VPM $\left(10.1 \mathrm{~cm} \mathrm{~s}^{-1}\right)$ and the CFM $\left(9.4 \mathrm{~cm} \mathrm{~s}^{-1}\right)$. The CNF $\left(6.7 \mathrm{~cm} \mathrm{~s}^{-1}\right)$ and the FDC $\left(5.0 \mathrm{~cm} \mathrm{~s}^{-1}\right)$ underestimate the drift velocities systematically. Obviously, this is caused by the impact of poor representation of internal ice forces. The VPM and the CFM are able to reproduce the pronounced variability on the monthly timescale with an RMS error of 1.3 and $1.4 \mathrm{~cm} \mathrm{~s}^{-1}$, respectively. Because of the systematic underestimation of drift speed both the CNF and the FDC yield high RMS errors of 3.6 and $5.6 \mathrm{~cm} \mathrm{~s}^{-1}$, respectively.

Evaluation of predicted ice thicknesses in Fram Strait is based on the ULS data in that region (Figure 6). The ULS data are located between $78^{\circ} \mathrm{N}$ and $80^{\circ} \mathrm{N}$ and cover the time period 1990-1995. As discussed earlier (section 3.2), the ice thickness in Fram Strait is underestimated slightly by most of the models. This may be caused 

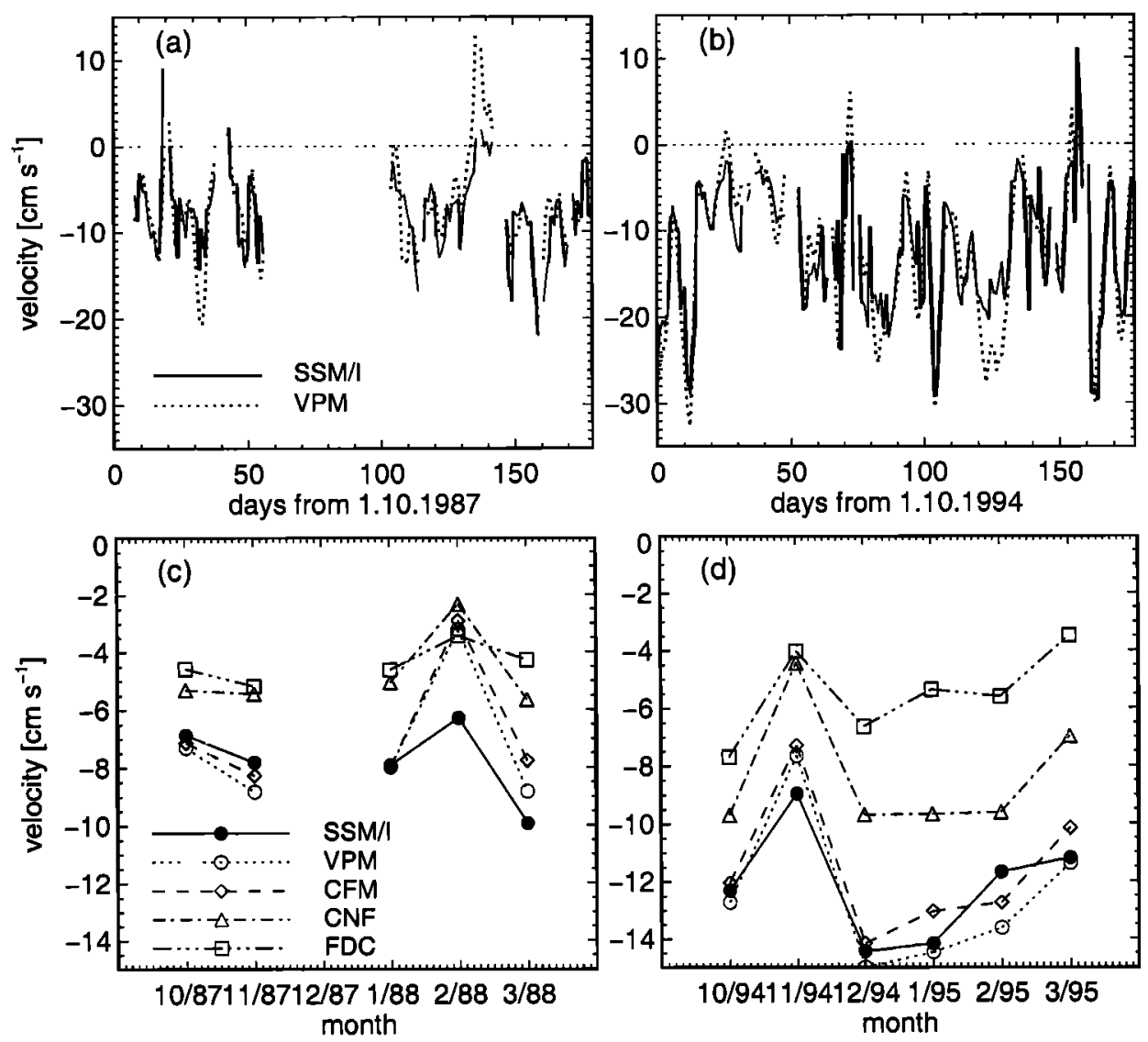

Figure 18. Comparison of the northward drift velocities in Fram Strait: $(a, b)$ time series of averaged 3 day velocities for the viscous-plastic model (VPM) and the satellite observations, (c, d) time series of monthly averaged velocities for all models and the observations. There are no SSM/I data available for some single days and for December 1987.

by the coarse spatial resolution. Spatial gradients of ice thickness in Fram Strait are large [Wadhams, 1983], and therefore even small displacements of the locations where model ice thicknesses are calculated have a great impact on the comparison.

The ice transport through Fram Strait is calculated for an almost zonal section consisting of aligned model grid cells at about $80^{\circ} \mathrm{N}$ from the northeastern tip of Greenland to the northwestern tip of Spitsbergen (Figure 3). Both the modeled ice drift and the ice thickness in Fram Strait are fundamental for a realistic simulation of the ice export through Fram Strait. Table 4 summarizes the results of total mean simulated ice transport through Fram Strait for the whole period 1979-1995. Additionally, observed and simulated drift speeds and ice thicknesses in that region are listed.

Vinje et al. [1998] estimate a mean ice export of $0.09 \mathrm{~Sv}$ based on velocities derived from satellite images for 1993-1995 and buoy velocities for the years 19761994, and ice maps and upward looking sonar measurements for 1990-1996. Considering the strong interannual variability of up to $130 \%$ [Vinje et al., 1998], the estimation, based on observations, is in good agreement with the model simulations except for the FDC.
The highest mean ice export of $0.094 \mathrm{~Sv}$ is simulated by the VPM. The CFM and CNF with about $0.086 \mathrm{~Sv}$ predict a smaller ice export than the VPM. This is caused by very low ice thicknesses in the case of the CFM, whereas the CNF "compensates" the significantly too small ice drift velocities with an overestimated ice thickness. The FDC predicts a very low ice export of $0.052 \mathrm{~Sv}$ due to a much too slow ice drift and a very small ice thickness.

These results show the pronounced impact of the assumed sea ice rheology on the ice transport through Fram Strait. This has consequences for the use of sea ice rheologies in coupled climate simulations because one of the major requirements for sea ice components is the simulation of accurate mass fluxes.

\section{Summary and Conclusions}

A hierarchy of four different sea ice rheology schemes has been evaluated with respect to a comprehensive set of observational data. All models run on the same grid with the same forcing and the same thermodynamic parameterizations. To allow for a fair intercomparison of the four rheologies, the ratio of drag coefficients was in- 
Table 4. Long-Term Mean Values of Ice Export Through Fram Strait and Drift Speed and Ice Thickness in Fram Strait

\begin{tabular}{|c|c|c|c|c|c|}
\hline & Observation & VPM & CFM & $\mathrm{CNF}$ & FDC \\
\hline Ice export, $\mathrm{Sv}$ & & 0.094 & 0.085 & 0.086 & 0.052 \\
\hline Drift speed, $\mathrm{cm} \mathrm{s}^{-1}$ & 10.2 & 10.1 & 9.4 & 6.7 & 5.0 \\
\hline Ice thickness, $\mathrm{m}$ & 2.6 & 2.1 & 1.8 & 2.8 & 2.2 \\
\hline
\end{tabular}

dividually optimized for each rheology model such that best agreement with basinwide mean drift speed and drift speed statistics was achieved. Individual optimization of this ratio was performed as a prerequisite to the intercomparison, for which the ratios were held fixed. A relatively small ratio is adequate for the cavitatingfluid model because the neglect of shear forces allows the sea ice to drift relatively fast. Highest ratios are required for the compressible Newtonian fluid and the free-drift model with velocity correction. The ratio of drag coefficients for the viscous-plastic model is in between the range of the other models. It should be noted that these results are the same whether optimizing daily or monthly mean drift speed.

A qualitative summary of the model performance for the investigated sea ice features is given in Table 5 . The viscous-plastic model, which is the physically most complete model, yields the best results in the model hierarchy. The direct comparison of simulated and observed drift velocity components shows that the viscousplastic model predicts the most realistic sea ice drift and drift speed statistics for averaging periods from days to months. However, a significant underestimation of the seasonal amplitude in the amount of drift stoppage is visible, which may be caused by the parameterization of large-scale ice strength. Ice drift in the Fram Strait region is strongly influenced by the internal sea ice stresses. The viscous-plastic model is able to reproduce the marked variability of drift velocities in this region with high accuracy. The anomalies of summer sea ice extent are simulated quite well by the viscousplastic model, whereas the winter anomalies cannot be realistically reproduced by any model, presumably a result of neglecting ocean variability.

Results for the cavitating-fluid model reflect the neglect of shear forces. The lack of shear strength enables sea ice drift parallel to coasts with no resistance. This leads to increased drift velocities at the northern coast of Greenland and the Canadian Archipelago and shifts the ice thickness maximum to the Beaufort Sea. The cavitating-fluid model is not able to force the ice drift to stop. This is obvious in the simulated drift-speed statistics, which show a low amount of drift speed stoppage for all seasons and regions of the Arctic. This substantiates the importance of shear strength in sea ice rheologies for large-scale applications. However, ice drift in Fram Strait is affected little by the missing shear strength, and therefore the simulated sea ice export through Fram Strait is nearly the same as in the viscous-plastic model.

While the spatial pattern of ice thickness for the compressible Newtonian fluid is similar to the viscousplastic model in most regions, the maximum ice thickness north of the Canadian Archipelago is much higher. This is not in accordance with observed climatologies. The reason for this discrepancy is the linear-viscous behavior of the Newtonian fluid, which is not able to prevent an excessive ice thickness buildup in regions with mainly convergent ice drift. This demonstrates the necessity of a plastic approach for a realistic sea ice rheology. Deficiencies of the linear-viscous rheology scheme show up also in the direct comparison of simulated and observed drift velocities for all timescales and the drift-speed histograms characterized by a smoothed peak of very slow drift speeds. Ice drift velocities are significantly too small in Fram Strait due to ice stresses hindering the divergent ice drift field in Fram Strait, which is caused by southwardly increasing drift velocities. The observed nonlinear behavior of sea ice, which allows opening of leads with only weak resistance and which resists convergent deformation with strong internal ice forces, must be included in an appropriate rheology approach.

The simplest model in the model hierarchy, the free-

Table 5. Performance of the Models for Investigated Sea Ice Properties

\begin{tabular}{lccrr}
\hline \multicolumn{1}{c}{ Sea Ice Property } & VPM & CFM & CNF & FDC \\
\hline Spatial pattern of ice thickness & + & - & -- & -- \\
Annual anomalies of ice thickness & ++ & + & + & ++ \\
Winter ice extent anomalies & - & - & - & - \\
Summer ice extent anomalies & + & - & - & - \\
Ice drift on different timescales & + & - & - & -- \\
Drift speed distributions & + & ++ & - & -- \\
Ice drift in Fram Strait & ++ & & & \\
\hline
\end{tabular}

Pluses, high performance; minuses, poor performance. 
Table 6. Impact of Ice Rheology on Properties of the Sea Ice Cover

\begin{tabular}{lr}
\hline \multicolumn{1}{c}{ Sea Ice Property } & Impact of Ice Rheology \\
\hline Spatial pattern of ice thickness & ++ \\
Annual anomalies of ice thickness & - \\
Winter ice extent anomalies & - \\
Summer ice extent anomalies & + \\
Ice drift on different timescales & ++ \\
Drift speed distributions & ++ \\
Ice drift in Fram Strait & ++ \\
\hline
\end{tabular}

Pluses, strong impact; minuses, no impact.

drift model with velocity correction, parameterizes the impact of ice strength by modifying drift velocities on the basis of local drift and ice thickness conditions without explicitly including ice forces in the momentum balance. This approach implies a number of deficiencies manifested in the poorest performance for almost all sea ice features. Because the spatial ice thickness distribution and large-scale ice drift pattern are poorly simulated, also freshwater fluxes, connected with the ice transport, cannot be simulated realistically by such a simple scheme.

In addition to the evaluation of the model hierarchy, the investigations demonstrate also how sensitive sea ice properties are to the applied sea ice rheology. The most sensitive properties being most useful for distinguishing between different rheologies. Our results, summarized in Table 6, show the following: The most sensitive sea ice properties with respect to rheology are the spatial pattern of ice thickness, the ice drift velocity on different timescales, drift speed statistics for different seasons and regions, and the ice drift in Fram Strait. Especially the spatial pattern of ice thickness would offer new possibilities for the evaluation of sea ice rheologies when basinwide observations for different seasons become available, for example, from submarines and remote sensing. Also, our investigations of ice drift for different averaging periods show that the performance of the models ditters with the timescale (Figure 15). Therefore comparisons should be made for both short (e.g., daily) and longer (e.g., monthly) timescales. Overall, the viscous-plastic rheology approach yields the most realistic simulation results within our tested model hierarchy. It is capable of reproducing the major sea ice properties such as spatial pattern of ice thickness, largescale ice drift, and ice export through Fram Strait. Of course, the four models in our hierarchy cover only a selection of the full range of sea ice models currently in use. There is ongoing development of sea ice models with a variety of yield curves and ice-strength parameterizations, faster or more accurate numerics, etc., which could (and should) be tested by similar means.

However, our four-model intercomparison points out which features a sea ice dynamics model should have for realistic simulation results: (1) Physically based models are superior to ad hoc schemes. (2) Plastic behavior of sea ice mechanics is essential. (3) Inclusion of shear forces is clearly an important improvement.

The viscous-plastic model with an elliptical yield curve is here considered a widely used representative for a class of sophisticated, physically based models. An intercomparison between these sophisticated models, for example, with different yield criteria, is a logical next step. Large-scale velocity fields from remote sensing images provide valuable new verification data for this future task because they allow the calculation of spatial derivatives of the ice drift.

A comparison of required computer resources shows that the good results obtained by the viscous-plastic model require a moderate increase in CPU time that is acceptable. There are several examples of the viscousplastic sea ice rheology being successfully integrated in coupled climate models. The parallel climate model (PCM) of the United States Department of Energy (DOE) includes a parallel version of the viscous-plastic model based on the eddy-resolving model of Y. Zhang of the Naval Postgraduate School, Monterey, California, which was optimized for massively parallel processor (MPP) architecture by T. Craig of NCAR, Boulder, Colorado. It is also planned to test the elastic-viscousplastic model of Hunke and Dukowicz [1997] as an alternate ice module in the PCM (according to the PCM homepage, http://www.cgd.ucar.edu/pcm). Another example is the coupled sea-ice-ocean model run by the work group of Gerdes et al. at the Alfred Wegener Institute, Bremerhaven, Germany (C. Köberle, personal communication, 1999). It consists of a viscous-plastic sea ice model coupled with the modular ocean model (MOM), version 2. This coupled model is run both as a regional and as a global model (on different grids) and can be run either in parallel or in nonparallel mode. The sea ice component requires a fraction of some 10 to $20 \%$ of the total CPU time when daily forcing is applied, and even less if lower-frequency forcing is used.

The computer time for any sea ice scheme in the present coupled simulations is minor compared to the oceanic and atmospheric components and should no longer be an argument against implementing realistic sea ice components in coupled models.

Acknowledgments. The daily forcing is derived from NCEP/NCAR reanalysis data which were obtained through the NOAA Climate Diagnostic Center and from ECMWF analyses for humidity. We thank Terje Brinck Loyning at the Norsk Polarinstitutt, Longyearbyen, Norway, for his help concerning references on ice thickness observations, Humfrey Melling at the Institute of Ocean Sciences, Sidney, B. C., Canada, for kindly providing additional ice thickness data, and Michael Hilmer at the Institut für Meereskunde, Kiel, Germany, for compiling the forcing data. Data on ice concentration were provided by the EOS Distributed Archive Center (DAC) at the National Snow and Ice Data Center (NSIDC), University of Colorado, Boulder. Buoy drift data were obtained from the International Arctic Buoy Program (IABP), and the SSM/I-derived drift fields were calculated by Thomas Martin at the Alfred-Wegener-Institut für Polar- 
und Meeresforschung, Bremerhaven, Germany. We thank Bernadette Fritzsch, Rüdiger Gerdes, William D. Hibler III, David M. Holland, Elizabeth C. Hunke, Cornelia Köberle, Jinlun Zhang, Yuxia Zhang, and the reviewers for their helpful comments. The Institut für Meereskunde Kiel, Germany, maintains the homepage of the Sea Ice Model Intercomparison Project: www.ifm.uni-kiel.de/me/SIMIP/simip.html. This article is AWI publication 1586.

\section{References}

Aagaard, K., and E. C. Carmack, The role of sea ice and other freshwater in the arctic circulation, J. Geophys. Res., 94, 14,485-14,498, 1989.

Agnew, T. A., H. Le, and T. Hirose, Estimation of largescale sea-ice motion from SSM/I $85.5 \mathrm{GHz}$ imagery, $A n n$. Glaciol., 25, 305-311, 1997.

Bourke, R. H., and A. S. McLaren, Contour mapping of Arctic Basin ice draft and roughness parameters, J. Geophys. Res., 97, 17,715-17,728, 1992.

Bryan, K., Climate and the ocean circulation, III, The ocean model, Mon. Weather Rev., 97(11), 806-826, 1969.

Campbell, W. J., The wind-driven circulation of sea ice, $J$. Geophys. Res., 70, 3279-3330, 1966.

Cavalieri, D. J., P. Gloersen, and W. J. Campbell, Determination of sea ice parameters with the Nimbus 7 SSMR, $J$. Geophys. Res., 89, 5355-5369, 1984.

Colony, R., and I. Rigor, Arctic ocean buoy data program report, Appl. Phys. Lab. Tech. Memo. APL-UW TM 10-91, Nat. Snow and Ice Data Cent. (NSIDC), Boulder, Colo., 1995.

Colony, R., and A. S. Thorndike, An estimate of the mean field of sea ice motion, J. Geophys. Res., 89, 10,62310,629, 1984.

Comiso, J. C., D. J. Cavalieri, C. L. Parkinson, and P. Gloersen, Passive microwave algorithm for sea ice concentration: A comparison of two techniques, Remote Sens. Environ., 60, 357-384, 1997.

Coon, M. D., G. A. Maykut, R. S. Pritchard, D. A. Rothrock, and A. S Thorndike, Modeling the pack ice as an elasticplastic material, AIDJEX Bull., 24, 1-105, 1974.

Dickson, R. R., J. Meincke, S. A. Malmberg and A. J. Lee, The "Great Salinity Anomaly" in the northern North Atlantic 1968-1982, Prog. Oceanogr., 20, 103-151, 1988.

Ebert, E. E., and J. A. Curry, An intermediate onedimensional thermodynamic sea ice model for investigating ice-atmosphere interactions, J. Geophys. Res., 98, 10,085-10,109, 1993.

Eicken, H., M. Lensu, M. Leppäranta, W. B. Tucker III, A. J. Gow, and O. Salmela, Thickness, structure, and properties of level summer multiyear ice in the Eurasian sector of the Arctic Ocean, J. Geophys. Res., 100, 22,697$22,710,1995$.

Fichefet, T., and M. A. Morales Maqueda, Sensitivity of a global sea ice model to the treatment of ice thermodynamics and dynamics, J. Geophys. Res., 102, 12,609-12,646, 1997.

Flato, G. M., and W. D. Hibler III, Modeling pack ice as a cavitating fluid, J. Phys. Oceanogr., 22, 626-651, 1992.

Geiger, C. A., W. D. Hibler, and S. F. Ackley, Large-scale sea ice drift and deformation: Comparison between models and observations in the western Weddell Sea during 1992, J. Geophys. Res., 103, 21,893-21,913, 1998.

Gloersen, P., and W. J. Campbell, Arctic and Antarctic sea ice, 1978-1987: Satellite passive-microwave observations and analysis, NASA SP, 511, 290 pp., 1992.

Gray, J. M. N. T., and P. D. Killworth, Stability of the viscous-plastic sea ice rheology, J. Phys. Oceanogr., 25(5), 971-978, 1995.
Groves, J. E., and W. J. Stringer, The use of AVHRR thermal infrared imagery to determine sea ice thickness within the Chukchi polynya. Arctic, 44(Suppl. 1), 130-139, Alberta, Canada, 1991.

Häkkinen, S., An Arctic source for the great salinity anomaly: A simulation of the Arctic ice-ocean system for 1955-1975, J. Geophys. Res., 98, 16,397-16,410, 1993.

Harder, M., Roughness, age and drift trajectories of sea ice in large-scale simulations and their use for model verifications, Ann. Glaciol., 25, 237-240, 1997.

Harder, M., Dynamik, Rauhigkeit und Alter des Meereises in der Arktis-Numerische Untersuchungen mit einem großskaligen Modell, Ber. Polarforsch. 203, AlfredWegener-Inst. für Polar- und Meeresforsch., Bremerhaven, Germany, 1996.

Harder, M., and H. Fischer, Sea ice dynamics in the Weddell Sea simulated with an optimized model, J. Geophys. Res., 104, 11,151-11,162, 1999 .

Harder, M., and P. Lemke, Modelling the extent of sea ice ridging in the Weddell Sea, in The Polar Oceans and Their Role in Shaping the Globai Environment, Geophys. Monogr. Ser., vol. 25, pp. 187-197, AGU, Washington, D. C., 1994

Harder, M., P. Lemke, and M. Hilmer, Simulation of sea ice transport through Fram Strait: Natural variability and sensitivity to forcing, J. Geophys. Res., 103, 5595-5606, 1998.

Hibler, W. D., III, A dynamic thermodynamic sea ice model, J. Phys. Oceanogr., 9(4), 815-846, 1979.

Hibler, W. D., III, Role of sea ice dynamics in modeling $\mathrm{CO}_{2}$ increases, in Climate Processes and Climate Sensitivity, Geophys. Manogr., vol. 29, edited by J. E. Hansen and T. Takahashi, pp. 238-253, AGU, Washington, D. C., 1984.

Hibler, W. D., III, and C. F. Ip, The effect of sea-ice rheology on Arctic buoy drift, in Ice Mechanics, vol. AMD-207, edited by J. P. Dempsey and Y. D. S. Rajapakse, pp. 255-263, Am. Soc. Mech. Eng., Appl. Mech. Div., New York, 1995

Hibler, W. D., III, and E. M. Schulson, On modeling sea-ice fracture and flow in numerical investigations of climate, Ann. Glacrol., 25, 26-32, 1997.

Hibler, W. D., III, and J. Zhang, Interannual and climatic characteristics of an ice ocean circulation model, in Ice and the Climate System, NATO ASI Ser. I, Global and Environ. Change, vol. 12, edited by W. R. Peltier, pp. 633-652, Springer-Verlag, New York, 1993.

Hilmer, M., M. Harder, and P. Lemke, Sea ice transport: A highly variable link between Arctic and North Atlantic, Geophys. Res. Lett., 25, 3359-3362, 1998

Hunke, E. C., and J. K. Dukowicz, An elastic-viscous-plastic model for sea ice dynamics, J. Phys. Oceanogr., 27(9), 1849-1867, 1997.

Intergovernmental Panel on Climate Change (IPCC), Climate Change, 1995: The Science of Climate Change, edited by J. T. Houghton, L. G. Meira Filho, B. A. Callander, N. Harris, A. Kattenberg, and K. Maskell, Cambridge Univ. Press, New York, 1996.

Ip, C. F., Numerical investigation of different rheologies on sea-ice dynamics, Ph. D. thesis, Thayer School of Eng. Dartmouth College, Hanover, N. H., 1993.

Kalnay, E., et al., The NCEP/NCAR 40-years reanalysis project, Bull. Am. Meteorol. Soc., 77(3), 437-470, 1996.

Kovacs, A., and J. S. Holladay, Development of an airborne sea ice thickness measurement system and field test results, CRREL Rep. 89-19, Cold Reg. Res. and Eng. Lab., Hanover, N. H., 1989.

Kreyscher, M., Dynamik des arktischen Meereises-Validierung verschiedener Rheologieansätze für die Anwen- 
dung in Klimamodellen, Ber. Polarforsch. 291, AlfredWegener-Inst. für Polar- und Meeresforsch., Bremerhaven, Germany, 1998.

Kreyscher, M., M. Harder, and P. Lemke, First results of the Sea-Ice Model Intercomparison Project (SIMIP), Ann. Glaciol., 25, 8-11, 1997.

Kwok, R., A. Schweiger, D. A. Rothrock, S. Pang, and C. Kottmeier, Sea ice motion from satellite passive microwave imagery assessed with ERS SAR and buoy motions, J. Geophys. Res., 103, 8191-8214, 1998.

Lemke, P., W. B. Owens, and W. D. Hibler III, A coupled sea-ice mixed-layer pycnocline model for the Weddell Sea, J. Geophys. Res., 95, 9513-9525, 1990.

Lemke, P., W. D. Hibler III, G. Flato, M. Harder, and M. Kreyscher, On the improvement of sea-ice models for climate simulations: The Sea-Ice Model Intercomparison Project, Ann. Glaciol., 25, 183-187, 1997.

Lewis, J. E., M. Lepparanta, and G. H. Granberg, Statistical properties of sea ice surface topography in the Baltic Sea, Tellus, Ser. A, 45(2), 127-142, 1993.

Martin, T., and E. Augstein, Large-scale drift of Arctic sea ice retrieved from passive microwave satellite data, J. Geophys. Res., in press, 2000.

Maslanik, J. A., M. S. Serreze, and R. G. Barry, Recent decreases in Arctic summer ice cover and linkages to atmospheric circulation anomalies, Geophys. Res. Lett., 23(13), 1677-1680, 1996.

McLaren, A. S., R. H. Bourke, J. E. Walsh, and R. L. Weaver, Variability in sea-ice thickness over the North Pole from 1958 to 1992, in The Polar Oceans and Their Role in Shaping the Global Environment, Geophys. Monogr. Ser., vol. 85, AGU, Washington, D. C., 1994.

McPhee, M. G., Ice-ocean momentum transfer for the AIDJEX ice model, AIDJEX Bull., 29, 93-111, 1975.

Melling, H., and D. A. Riedel, Development of seasonal pack ice in the Beaufort Sea during the winter of 1991-1992: a view from below, J. Geophys. Res., 101, 11,975-11,991, 1996.

Moritz, R. E., ULS measurements of ice draft in the Chukchi Sea, Data Report of Polar Science Center, Univ. of Washington, Seattle, 1990.

Oberhuber, J. M., The OPYC Ocean General Circulation Model, Tech. Rep. 7, Dtsch. Klimarechenzent. GmbH, Hamburg, Germany, 1992.

Parkinson, C. L., and W. M. Washington, A large-scale numerical model of sea ice, J. Geophys. Res., 84, 311-337, 1979.

Pollard, D., and S. L. Thompson, Sea-ice dynamics and $\mathrm{CO}_{2}$ sensitivity in global climate models, Atmos.-Ocean, 32 (2), 449-467, Downsview, Ontario, Canada, 1994.

Rind, D., R. Healy, C. Parkinson, and D. Martinson, The role of sea ice in $2 \times \mathrm{xO} 2$ climate model sensitivity, part II, Hemisphere dependence of sea ice thickness and extent, Geophys. Res. Lett., 24, 1491-1494, 1997.

Rothrock, D. A., The energetics of the plastic deformation of pack ice by ridging, $J$. Geophys. Res., 80(30), 4514-4519, 1975.
Rothrock, D. A., Y. Yu, and G. A. Maykut, Thinning of the Arctic sea-ice cover, Geophys. Res. Lett., 26, 1-5, 1999.

Semtner, A. J., Jr., A model for the thermodynamic growth of sea ice in numerical investigations of climate, $J$. Phys. Oceanogr., 6(3), 379-389, 1976.

Serreze, M. C., J. A. Maslanik, J. R. Key, R. F. Kokaly, and D. A. Robinson, Diagnosis of the record minimum in Arctic sea ice area during 1990 and associated snow cover extremes, Geophys. Res. Lett., 22(16), 2183-2186, 1995.

Steele, M., J. Zhang, D. Rothrock, and H. Stern, The force balance of sea ice in a numerical model of the Arctic Ocean, J. Geophys. Res., 102, 21,061-21,079, 1997.

Steiner, N., M. Harder, and P. Lemke, Modelling sea ice roughness in the Arctic, in Ice physics in the natural and endangered environment, NATO ASI Ser. I, vol. 56, edited by Wettlaufer, J., J. G. Dash, and N. Untersteiner, pp. 341-346, Springer-Verlag, New York, 1998.

Thorndike, A. S., Thickness distribution of sea ice, J. Geophys. Res., 80, 4501-4513, 1975.

Thorndike, A. S., and R. Colony, Sea ice motion in response to geostrophic winds, J. Geophys. Res., 87, 5845-5852, 1982.

Ukita J., and R. E. Moritz, Yield curves and flow rules of pack ice, J. Geophys. Res., 100, 4545-4557, 1995.

Vinje, T., N. Nordlund, and A. Kvambekk, Monitoring ice thickness in Fram Strait, J. Geophys. Res., 103, 10,437$10,450,1998$.

Vowinckel, E., and S. Orvig, The climate of the North Polar Basin, in Climates of the Polar Regions, World Surv. Climatol., vol. 14, edited by S. Orvig, New York, 1970.

Wadhams, P., Sea ice thickness distribution in Fram Strait, Nature, 305, 108-111, 1983.

Wadhams, P., Ice thickness in the Arctic Ocean: The statistical reliability of experimental data, J. Geophys. Res., 102, 27,951-27,959, 1997.

Weaver, R., C. Morris, and R. G. Barry, Passive microwave data for snow and ice research: Planned products from the DMSP SSM/I system, American Geophysical Union, Wash., D.C., Eos Trans. $A G U, 68(39), 769,776,777$, 1987.

Zhang, J., and W. D. Hibler III, On an efficient numerical method for modeling sea ice dynamics, J. Geophys. Res., 102, 8691-8702, 1997.

G. M. Flato, Canadian Centre for Climate Modelling and Analysis, Atmospheric Environment Service, University of Victoria, P.O. Box 1700, Victoria, BC V8W 2Y2, Canada. (e-mail: gflato@ec.gc.ca)

M. Harder and P. Lemke, Institut für Meereskunde an der Universität Kiel, Düsternbrooker Weg 20, D24105 Kiel, Germany. (e-mail: mharder@ifm.uni-kiel.de; plemke@ifm.uni-kiel.de)

M. Kreyscher, Alfred-Wegener-Institut für Polar- und Meeresforschung, Bürgermeister Smidt-Str. 20, D-27568 Bremerhaven, Germany.

(Received June 3, 1999; revised November 5, 1999; accepted December 28, 1999.) 